\title{
Development of Rapid Isothermal Amplification Assays for Detection of Phytophthora spp. in Plant Tissue
}

\author{
Timothy D. Miles, Frank N. Martin, and Michael D. Coffey
}

First and second authors: United States Department of Agriculture-Agricultural Research Service, Crop Improvement and Protection Research Unit, Salinas, CA 93905; and third author: Department of Plant Pathology and Microbiology, University of California, Riverside 92521.

Accepted for publication 24 August 2014.

\begin{abstract}
Miles, T. D., Martin, F. N., and Coffey, M. D. 2015. Development of rapid isothermal amplification assays for detection of Phytophthora spp. in plant tissue. Phytopathology 105:265-278.

Several isothermal amplification techniques recently have been developed that are tolerant of inhibitors present in many plant extracts, which can reduce the need for obtaining purified DNA for running diagnostic assays. One such commercially available technique that has similarities with real-time polymerase chain reaction (PCR) for designing primers and a labeled probe is recombinase polymerase amplification (RPA). This technology was used to develop two simple and rapid approaches for detection of Phytophthora spp.: one genus-specific assay multiplexed with a plant internal control and the other species-specific assays for Phytophthora ramorum and P. kernoviae. All assays were tested for sensitivity (ranging from $3 \mathrm{ng}$ to $1 \mathrm{fg}$ of DNA) and specificity using DNA extracted from more than 136 Phytophthora taxa, 21 Pythium

all pathogen RPA assays. Six different extraction buffers were tested for use during plant tissue maceration and the assays were validated in the field by collecting 222 symptomatic plant samples from over 50 different hosts. Only 56 samples were culture positive for Phytophthora spp. whereas 91 were positive using the Phytophthora genus-specific RPA test and a TaqMan real-time PCR assay. A technique for the generation of sequencing templates from positive RPA amplifications to confirm species identification was also developed. These RPA assays have added benefits over traditional technologies because they are rapid (results can be obtained in as little as $15 \mathrm{~min}$ ), do not require DNA extraction or extensive training to complete, use less expensive portable equipment than PCR-based assays, and are significantly more specific than current immunologically based methods. This should provide a rapid, field-deployable capability for pathogen detection that will facilitate point-of-sample collection processing, thereby reducing the time necessary for accurate diagnostics and making management decisions.
\end{abstract} spp., 1 Phytopythium sp., and a wide range of plant species. The lower limit of linear detection using purified DNA was 200 to $300 \mathrm{fg}$ of DNA in

The genus Phytophthora contains some of the most economically devastating plant pathogens on a wide range of host plants, including agricultural crops (14) and forest trees $(3,32)$. Diseases caused by Phytophthora spp. include root, stem, crown, and fruit rots and are sometimes difficult to distinguish from other plant pathogens based on symptoms alone (23). In recent years, significantly more species diversity has been identified in the genus Phytophthora as molecular data have differentiated taxonomically distinct groups $(7,24)$ and new species have been identified in aquatic ecosystems $(16,20,26)$. Certain Phytophthora diseases are particularly important, such as sudden oak death caused by $P$ hytophthora ramorum, a quarantine pathogen which has had a devastating effect on forest ecosystems in several coastal communities, primarily in California and in parts of continental Europe and the United Kingdom (32). This pathogen was also introduced into the nursery production systems of these countries, which has aided in its distribution. Additionally, in 2003, during surveys for P. ramorum, a new species later identified as $P$. kernoviae was isolated in the United Kingdom from Rhododendron spp. showing leaf and stem necrosis in a woodland area near a commercial nursery. This

Corresponding author: F. N. Martin; E-mail address: frank.martin@ars.usda.gov

* The $e$-Xtra logo stands for "electronic extra" and indicates that the online version contains two supplemental figures and two supplemental sequence alignment files.

http://dx.doi.org/10.1094/PHYTO-05-14-0134-R

This article is in the public domain and not copyrightable. It may be freely reprinted with customary crediting of the source. The American Phytopathological Society, 2015.
Additional keywords: sudden oak death.

species could pose a new threat to trees and woodlands in the United States (8).

Currently, Phytophthora spp. are detected in a variety of ways, including traditional isolation on selective media, baiting, immunodetection assays, and conventional polymerase chain reaction (PCR) and real-time PCR assays (18,23). Enzyme-linked immunosorbent assay (ELISA) is commonly used to detect Phytophthora at a genus-specific level utilizing a generic Phytophthora antigen. This technique has successfully detected Phytophthora spp. on a variety of plant material and in diverse environments such as irrigation water and soil $(2,23)$ but it is important to note that background detection of some Pythium spp. may occur as well $(1,22)$. Species-specific Phytophthora PCR markers have been developed that target several nuclear loci (23), including the internal transcribed spacer $(15,17,34)$, ras-related protein Ypt1 $(28,29), \beta$-tubulin and elicitin $(4,6)$, and mitochondrial loci like the coxl-2 spacer region (25). A few genus-specific PCR based marker systems have also been developed $(4,13,21,25,28)$; however, some have shown cross reactivity with nontarget members of the subclass Peronosporomycetidae, particularly Pythium spp. $(4,21)$, or are not suitable for real-time PCR $(13,25,28)$.

Most of the aforementioned detection techniques require a significant time investment for DNA extraction and running the diagnostic assay in the lab or incubation periods to grow the pathogen on media. The ability to identify a Phytophthora sp. without the need for a DNA extraction in a short period of time with minimal laboratory equipment would be an important asset to field and laboratory diagnosticians. Isothermal amplification, or the ability to amplify DNA without the aid of a thermocycling 
apparatus, has the potential to deliver this detection capability. Isothermal amplification reactions incubate at a fixed temperature and are generally more tolerant of inhibitors that reduce the amplification efficiency of PCR (11). The most popular technique is loop-mediated-isothermal amplification (LAMP), and several species-specific assays for Phytophthora have been developed using LAMP, including $P$. ramorum, $P$. kernoviae, $P$. melonis, and $P$. sojae $(9,12,30)$. Although LAMP technology can be effective, assays can be difficult to design and many of the current assays that have been developed utilize a lateral flow device for detection, which dramatically increases the overall cost. Other techniques such as helicase-dependent amplification (Biohelix Corp., Beverly, MA) utilize two primers and a probe but the technology is proprietary and only a handful of assays are currently available for various foodborne pathogens (33). Recombinase polymerase amplification (RPA) (TwistDx Ltd., Cambridge, UK) is another isothermal technology and kits are available in several formats for development of user-designed assays. The kits are supplied with a lyophilized pellet containing reagents; therefore, all that is needed to prepare an amplification is addition of supplied hydration buffer and user-supplied primers, probe, and $1 \mu \mathrm{l}$ of sample. To initiate amplification, magnesium acetate is added and mixed and the tube placed in a data collection unit held at $39^{\circ} \mathrm{C}$. To ensure a more even distribution of RPA amplicons during amplification and maximum sensitivity, the manufacturer recommends removing the tube after $4 \mathrm{~min}$ and mixing again prior to replacement into the data collection unit. The TwistAmp exo kit utilizes two primers 30 to $35 \mathrm{bp}$ long and a labeled probe (46 to $52 \mathrm{bp}$ ) to generate an amplicon under $500 \mathrm{bp}$. RPA is similar to TaqMan real-time PCR in that it offers multiplexed real-time fluorescent DNA detection with FAM- and TAM-labeled probes (although the signal for TAM is much lower than FAM) (27), usually within 5 to $25 \mathrm{~min}$.

Bilodeau et al. (5) recently reported on a systematic approach for development of genus and species-specific TaqMan assays for Phytophthora utilizing mitochondrial gene-order differences between Phytophthora spp. and similar organisms (i.e., Pythium and plant species) to enhance specificity. Highly conserved primers amplified a spacer region and flanking coding regions between the atp9-nad9 genes that contained a conserved annealing site for a genus-specific TaqMan probe and variable spacer sequences for development of species-specific TaqMan probes. A second locus, trnM-trnP-trnM, was also a highly conserved gene order and was highly specific for detection of Phytophthora spp. at a genus level using the same approach as with the atp9-nad9 locus. Based on the specificity and sensitivity of the TaqMan real-time PCR assays that were developed and sequence polymorphisms observed, these loci were chosen as targets for development of an RPA diagnostic assay. The goal of this study was to (i) develop an RPA Phytophthora genus-specific detection assay; (ii) identify compatible crude tissue extraction buffers for the RPA system; (iii) develop a systematic approach to construct species-specific RPA markers, particularly for $P$. ramorum and $P$. kernoviae; (iv) develop a method to confirm the identification of the species present in a positive RPA method by DNA sequencing; and (v) develop a rapid, field-portable diagnostic assay that could be used directly at the point of sample collection.

\section{MATERIALS AND METHODS}

Phytophthora, Pythium, Phytopythium, and plant species used. In total, 155 Phytophthora isolates were used in this study, representing 136 taxa. These isolates included three different subspecies of $P$. alni (alni, multiformis and uniformis), three phylogenetic groups of $P$. cryptogea (GI, GII, and sp. kelmania GIII), six phylogenetically distinct species (sp. aff. brassicae-1, sp. aff. brassicae-2, sp. aff. colocasiae-1, sp. aff. erythroseptica, sp. aff. siskiyouensis, cinnamomi var. robiniae, and citricola clade
E) and two naturally occurring hybrids $(P . \times$ pelgrandis and $P$. $\times$ serendipita) $(19,24)$. All Phytophthora isolates were obtained and are available from the World Phytophthora Genetic Resource Collection at the University of California, Riverside (http:// phytophthora.ucr.edu/databasemain.html). In order to check for specificity, 21 Pythium spp., 1 Phytopythium sp., and 6 plant species were tested initially (Table 1). Additional information about the Pythium and Phytopythium isolates can be found in Martin et al. (25).

Sequence alignments of mitochondrial loci used for targets were constructed using the software program Geneious (v.4.7.6; Biomatters Ltd., Auckland, New Zealand), and included the trnMtrnP-trnM, and atp9-nad9 regions present in Phytophthora spp. and the coxl region in plants (for development of a plant internal control). The total number of sequences used to develop the marker system was 174 (representing approximately 120 Phytophthora taxonomic entities) for trnM-trnP-trnM, 633 (including multiple isolates of the same species to assess intraspecific variation in the target) for atp9-nad9, and 28 plant taxa for the cox 1 region, which is highly conserved across a broad range of plant species. Additional information on how these sequences were obtained can be found in Bilodeau et al. (5). Primers were primarily designed manually based on alignments; however, melting temperature and GC\% were calculated using the OligoAnalyzer Tool 3.1 (Integrated DNA Technologies, Inc., Coralville, IA).

Various DNAs were obtained from the World Phytophthora Collection at a concentration of $10 \mathrm{ng} / \mu \mathrm{l}$. This concentration was verified periodically using a Nanodrop (Thermo Fisher Scientific, Waltham, MA) instrument. However, for all standard curve plots and limit of detection information provided in this study, a Qubit Florometer and the Quant-iT dsDNA HS Assay Kit (Invitrogen, Carlsbad, CA) were utilized following the manufacturer's instructions, using $10 \mu \mathrm{l}$ of DNA at $1 \mathrm{ng} / \mu \mathrm{l}$ (based on initial NanoDrop values).

Marker design for RPA. In order to develop a Phytophthora genus-specific assay using the TwistAmp exo kit (TwistDx), the trnM-trnP-trnM region of the mitochondrial genome was chosen because of its length; in addition, this gene order is highly conserved in all Phytophthora spp. but not present in plants or Pythium or Phytopythium spp. (5). Six forward and six reverse primers were designed (between 25 and $35 \mathrm{bp}$ ) to test various combinations and lengths and TrnM-F and TrnM-R were chosen for the greatest sensitivity and specificity. A probe for this assay was also developed, labeled with a FAM dye and Black Hole Quencher 1, and placed near the forward primer in the first trnM (TWGM-P1) (Fig. 1A; Table 2). These primers and probes were designed by following the recommendations of the TwistAmp exo kit manufacturer.

For the Phytophthora species-specific assays using the TwistAmp exo kit (P. kernoviae and P. ramorum), the atp9-nad9 region in the mitochondrial genome was chosen because of the level of interspecific sequence polymorphisms observed and the fact that this gene order is not present in plants or Pythium or Phytopythium spp. (5). Two forward primers were tested and the most sensitive and specific one became the common forward primer (Atp9-F). Furthermore, a genus-specific probe labeled with a FAM dye and Black Hole Quencher 1 (Atp9-P) was also designed in the atp 9 gene near the forward primer, following the recommendations of the kit manufacturer. Species-specific reverse primers were placed in the atp9-nad9 spacer region (Atp9Nad9-Pkern-R and Atp9Nad9-Pram-R) (Fig. 1B; Table 2).

For a plant internal control to multiplex with the Phytophthora genus-specific assay to check the quality of the DNA in crude tissue extractions, the coxl gene was chosen because it was used previously as an internal control in Phytophthora PCR assays $(5,25,31)$ and has been shown to work with a broad range of plant species. Various combinations of two forward and two reverse primers were tested and Cox1-IPC-F and Cox1-IPC-R were 
chosen for the greatest sensitivity and specificity. A probe for this assay was also developed, and labeled with a TAMRA dye and Black Hole Quencher 2 (Cox1-IPC-P) (Fig. 1C; Table 2). All primers and probes used in this study were obtained from Integrated DNA Technologies, Inc. and Biosearch Technologies, Inc. (Petaluma, CA), respectively.

RPA and TaqMan amplification. For all RPA assays, DNA was pipetted into separate eight-well strip tubes $(200 \mu \mathrm{l}$ in volume), master mix was added and mixed, then transferred to an eight-well strip of the TwistAmp exo kit containing lyophilized reagents and magnesium acetate was applied to the cap. Reactions were centrifuged briefly to uniformly initiate the reaction with the added $\mathrm{Mg}^{+2}$, mixed by inversion to ensure even distribution of $\mathrm{Mg}^{+2}$, briefly centrifuged again, and placed in the Twista (TwistDx) detection device. All assays were carried out at $39^{\circ} \mathrm{C}$ for a period of $30 \mathrm{~min}$ and fluorometric data were collected every $20 \mathrm{~s}$, per the manufacturer's recommendations. To evenly distribute the amplicons throughout the RPA reaction during amplification, data collection was paused after $4 \mathrm{~min}$ and the tubes were removed, mixed by inversion, centrifuged, and placed back into the Twista device for continued data collection, causing a loss of a minute of data. A sample was judged as positive or negative during a range of 6 to 25 min using the slope validation evaluation of the Twista Studio software (version 2.06.06), with the following slope validation parameters: four time points or periods collected and an overall slope (in $\mathrm{mV} / \mathrm{min}$ ) of 30 and 12 for the Phytophthora and plant internal control RPA assays, respectively. The time point at which an amplification was classified as positive is referred to as the onset of amplification. This was calculated by subtracting the preagitation step of $5 \mathrm{~min}$ from the onset of amplification; then, the $\log$ of this value was calculated. This value was termed the log of the onset of amplification (OT) and was then was plotted against the log of concentration.

A 50- $\mu$ l reaction of the multiplexed RPA assay for Phytophthora genus specificity and the plant internal control contained the following reagents (primers and probes were all at an initial concentration of $10 \mu \mathrm{M}$ ): $0.1 \mu \mathrm{l}$ of TrnM-F, $2.9 \mu \mathrm{l}$ of TRNM-R, $1.25 \mu \mathrm{l}$ of Cox1-IPC-F and Cox1-IPC-R, $0.6 \mu \mathrm{l}$ of TrnM-P and Cox1-IPC-P, $29.5 \mu \mathrm{l}$ of rehydration buffer, $10.3 \mu \mathrm{l}$ of DNase-free water, $1 \mu \mathrm{l}$ of template, and $2.5 \mu \mathrm{l}$ of $280 \mathrm{mM}$ magnesium acetate.

For the species-specific assays ( $P$. ramorum and $P$. kernoviae), a $50-\mu$ reaction contained the following reagents (primers and probes were all at an initial concentration of $10 \mu \mathrm{M}): 29.5 \mu \mathrm{l}$ of rehydration buffer, $11.9 \mu \mathrm{l}$ of DNase-free water, $1 \mu \mathrm{l}$ of template, $2.5 \mu \mathrm{l}$ of $280 \mathrm{mM}$ magnesium acetate, and $0.6 \mu \mathrm{l}$ of Atp9-F and $3.6 \mu$ of Atp9Nad9-Pram-R for P. ramorum or $0.2 \mu$ of Atp9-F and $4.0 \mu \mathrm{l}$ of Atp9Nad9-Pkern-R for P. kernoviae.

Testing various crude extraction buffers. Several extraction buffers were tested for their effectiveness to extract DNA from plant tissue samples for RPA assays. Five ELISA grinding buffers were tested, including two from Agdia, Inc. (Elkhart, IN), GEB2 (ACC 00130) and GEB3 (ACC 00360); and a standard ELISA grinding buffer (containing $100 \mathrm{ml}$ of $10 \times$ phosphate-buffered saline buffer, $2 \mathrm{~g}$ of bovine serum albumen, $20 \mathrm{~g}$ of PVP-40, and $0.5 \mathrm{ml}$ of Tween 20 , brought to a final volume of 1 liter) at various $\mathrm{pH}$ levels $(8.0,9.5$, and 11.0). Additionally, a polyethylene glycol (PEG) buffer (containing $60 \mathrm{~g}$ of PEG 200 with $0.93 \mathrm{ml}$ of $2 \mathrm{M} \mathrm{KOH}$ and $39 \mathrm{ml}$ of water at $\mathrm{pH} \mathrm{13.5)} \mathrm{was} \mathrm{also}$ tested (10). All six buffers were tested by taking $0.5 \mathrm{~g}$ of fresh Fragaria $\times$ ananassa crown tissue and $5 \mathrm{ml}$ of extraction buffer and macerating the tissue in a plastic mesh bag (ACC 00930; Agdia, Inc.) with a tissue homogenizer tool (ACC 00900; Agdia,
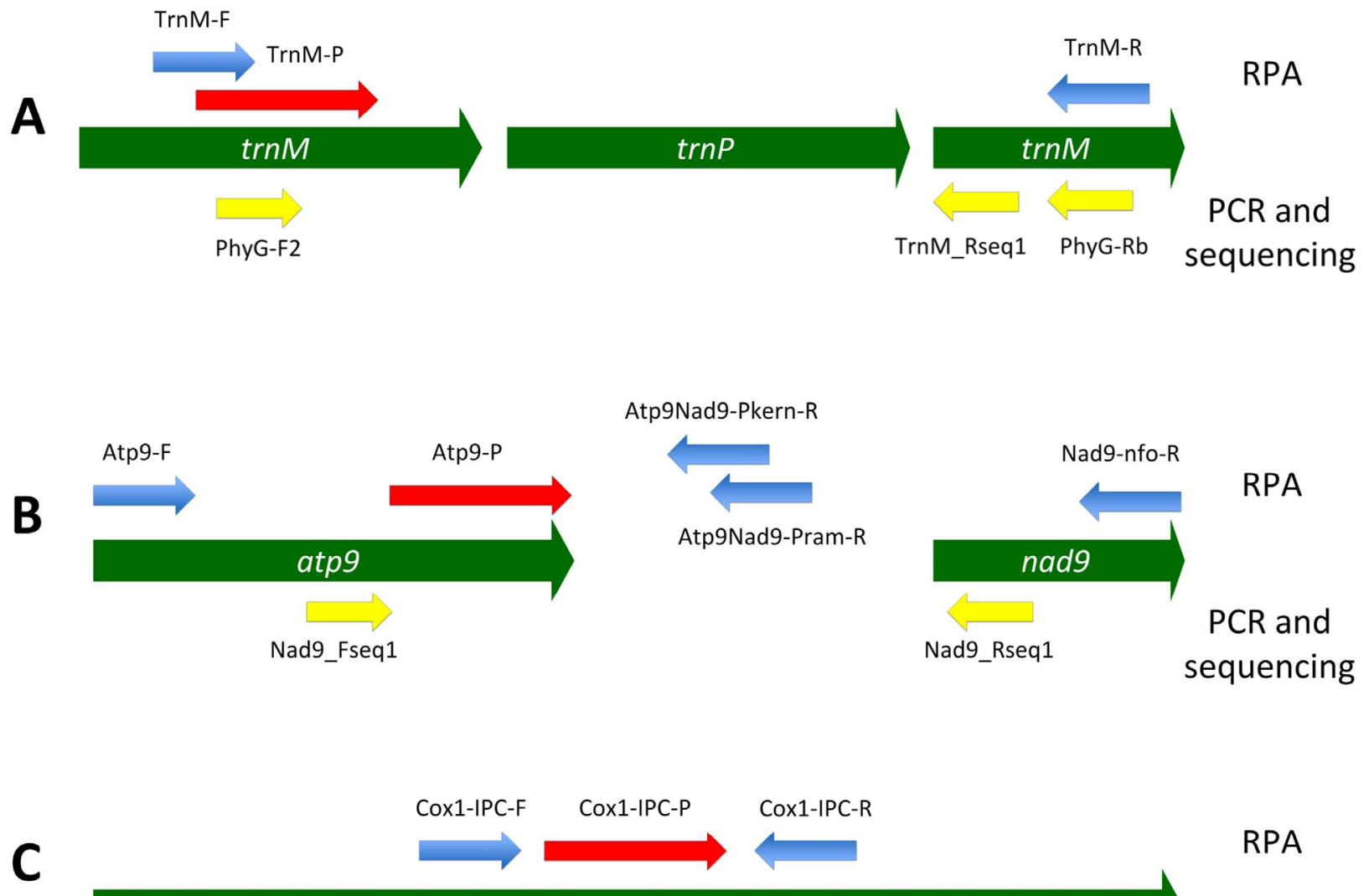

RPA

$\operatorname{cox} 1$

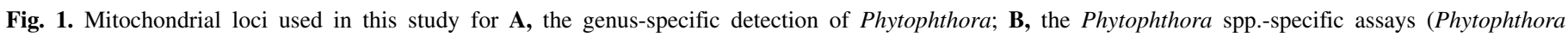

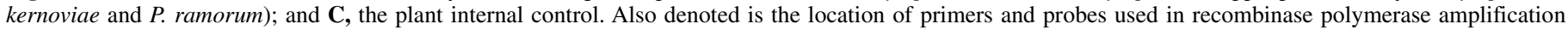

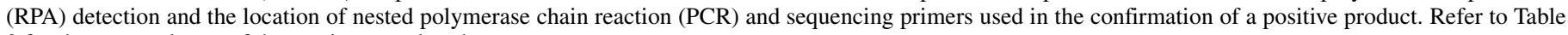
2 for the nomenclature of these primers and probes. 
TABLE 1. List of Phytophthora, Pythium, Phytopythium, and plant species included in this investigation, their isolate numbers, and origin of recovery

\begin{tabular}{|c|c|c|c|}
\hline Species & Isolate number ${ }^{\mathrm{a}}$ & Host species & Country \\
\hline \multicolumn{4}{|l|}{ Phytophthora spp. } \\
\hline sp. aff. brassicae-1 & P10728 & Daucus carota & France \\
\hline sp. aff. brassicae-2 & P6207 & Allium cepa & Switzerland \\
\hline sp. aff. colocasiae-1 & $\mathrm{P} 10341$ & Syringa sp. & England \\
\hline sp. aff. erythroseptica & P10811 & Zantedeschia aethiopica & Japan \\
\hline sp. aff. siskiyouensis & P1200 & Theobroma cacao & Brazil \\
\hline sp. brasilensis & P0630 & Theobroma cacao & Brazil \\
\hline sp. cuyabensis & P8213 & $\ldots$ & Ecuador \\
\hline sp. hungarica & $\mathrm{P} 10281$ & $\ldots$ & Hungary \\
\hline sp. kelmania (P. cryptogea GIII) & P10613 & Abes fraseri & United States \\
\hline sp. erwinii & P3132 & Banksia integrifolia & Australia \\
\hline sp. napoensis & P8221 & $\ldots$ & Ecuador \\
\hline sp. ohioensis & P16050 & $\ldots$ & United States \\
\hline sp. personii & P11555 & Nicotiana tabacum & United States \\
\hline sp. PgChlamydo & P10669 & Idesia polycarpa & New Zealand \\
\hline sp. sulawesiensis & P6306 & Syzygium aromaticum & Indonesia \\
\hline sp. thermophium & P10457 & $\ldots$ & United States \\
\hline alni subsp. alni & P16203 & Alnus glutinosa & The Netherlands \\
\hline alni subsp. multiformis & P16202 & $\ldots$ & $\ldots$ \\
\hline alni subsp. uniformis & P16206 & Alnus sp. & Sweden \\
\hline alticola & P16948, P19861 & $\ldots$ & $\ldots$ \\
\hline amnicola & P19862 & $\ldots$ & $\ldots$ \\
\hline andina & $\mathrm{P} 13365$ & Solanum brevifolium & Ecuador \\
\hline asiatica & P19977 & $\ldots$ & $\ldots$ \\
\hline asparagi & P10690 & Asparagus officinalis & New Zealand \\
\hline austrocedrae & P15132 & Austrocedrus chilensis & Argentina \\
\hline bahamensis & P3930 & $\ldots$ & Bahamas \\
\hline bisheria & P10117 & Fragaria sp. & United States \\
\hline boehmeriae & P6950 & Boehmeriae nivea & Taiwan \\
\hline botryosa & P3425 & Hevea brasiliensis & Malaysia \\
\hline brassicae & P10414 & Brassica oleraceae & The Netherlands \\
\hline cactorum & $\mathrm{P} 0714$ & Syringa vulgaris & The Netherlands \\
\hline cajani & P3105 & Cajanus cajani & India \\
\hline cambivora & P0592 & Abies procera & United States \\
\hline canalensis & P10456 & $\ldots$ & United States \\
\hline capensis & P1819 & Curtisia dentata & South Africa \\
\hline capsici & P3605 & Capsicum annuиm & United States \\
\hline captiosa & P10719 & Eucalyptus saligna & New Zealand \\
\hline cichorii & P19844 & $\ldots$ & $\ldots$ \\
\hline cinnamomi & P2110 & Cinnamomum burmannii & Indonesia \\
\hline cinnamomi var. robiniae & P16350 & Robinia pseudoacacia & China \\
\hline citricola & P0716, P6880 & Citrus sinensis, Fragaria $\times$ ananassa & Taiwan, Bulgaria \\
\hline citricola clade $\mathrm{E}^{\mathrm{b}}$ & P1321 & Rubus sp. & United States \\
\hline citrophthora & P6310, P0318 & Theobroma cacao, Citrus & Indonesia, Australia \\
\hline clandestina & P3942 & Trifolium subterraneum & Australia \\
\hline colocasiae & P6317 & Colocasia esculenta & Indonesia \\
\hline cryptogea $G I$ & P1088, P7788 & Callistephus chinensis, Daucus carota & United States, United Kingdom \\
\hline cryptogea GII & P3103 & Solanum marginatum & Ecuador \\
\hline dauci & P19845 & $\ldots$ & $\ldots$ \\
\hline drechsleri & P10331 & Gerbera jamesonii & United States \\
\hline elongata & P19597 & $\ldots$ & $\ldots$ \\
\hline erythroseptica & P1699 & Solanum tuberosum & United States \\
\hline europaea & P10324 & Quercus rhizosphere & France \\
\hline fallax & P10725 & Eucalyptus fastigata & New Zealand \\
\hline fluvialis & P19584 & $\ldots$ & $\ldots$ \\
\hline foliorum & P10969 & Rhododendron sp. & United States \\
\hline fragariae & P3821 & Fragaria $\times$ ananassa & United Kingdom \\
\hline frigida & P16059 & Eucalyptus sp. & South Africa \\
\hline gallica & P16826 & $\ldots$ & $\ldots$ \\
\hline gemini & P15880 & Zostera marina & The Netherlands \\
\hline gibbosa & P19586, P19587 & $\ldots$ & $\ldots$ \\
\hline glovera & P10619 & Nicotiana tabacum & Brazil \\
\hline gonapodyides & P6135 & Ilex sp. & United Kingdom \\
\hline gregata & P19588 & $\ldots$ & $\ldots$ \\
\hline hedraiandra & P11056 & Rhododendron sp. & United States \\
\hline heterospora & P19902, P19903 & $\ldots$ & $\ldots$ \\
\hline heveae & P3428, P1000, P0578 & Hevea brasiliensis, Persea americana, Theobroma cacao & Malaysia, Guatemala, Malaysia \\
\hline \multirow[t]{2}{*}{ hibernalis } & P3822 & Citrus sinensis & Australia \\
\hline & & & (continued on next page) \\
\hline
\end{tabular}

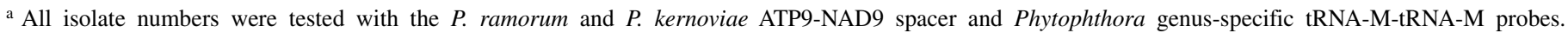
Additional information on isolates (hosts) may be obtained at the website for the World Phytophthora Genetic Resource Collection at the University of California, Riverside (http://phytophthora.ucr.edu/databasemain.html).

b $P$. citricola clade E refers to the classification of Jung and Burgess (19).

c Background information on Pythium isolates used in this study can be found in Martin et al. (25). 
TABLE 1. (continued from preceding page)

\begin{tabular}{|c|c|c|c|}
\hline Species & Isolate number ${ }^{\mathrm{a}}$ & Host species & Country \\
\hline himasilva & P19820 & $\ldots$ & $\ldots$ \\
\hline humicola & P3826 & $\ldots$ & Taiwan \\
\hline hydropathica & P16857 & $\ldots$ & United States \\
\hline idaei & P6767 & Rubus idaeus & United Kingdom \\
\hline ilicis & P3939 & Ilex sp. & Canada \\
\hline infestans & $\mathrm{P} 10650$ & Solanum tuberosum & Mexico \\
\hline insolita & P6195 & $\ldots$ & Taiwan \\
\hline inundata & P8478 & Aesculus hippocastanum & United Kingdom \\
\hline ipomoeae & P10225 & Ipomoea longipedunculata & Mexico \\
\hline iranica & P3882 & Solanum melongena & Iran \\
\hline irrigata & P16861 & $\ldots$ & United States \\
\hline katsurae & P10187, P1372, P15169 & Castanea crenata, Cocos nucifera, Agathis australis & Japan, United States, New Zealand \\
\hline kernoviae & P10681 & Annona cherimola & New Zealand \\
\hline lactucae & P19872, P19875 & $\ldots$ & $\ldots$ \\
\hline lacustris & P10337 & Salix matsudana & United Kingdom \\
\hline lagoariana & P8217 & $\ldots$ & Ecuador \\
\hline lateralis & P3888 & Chamaecyparis lawsoniana & United States \\
\hline litoralis & P19590, P19591 & $\ldots$ & $\ldots$ \\
\hline macrochlamydospora & P10267 & Glycine max & Australia \\
\hline meadii & P6128, P6262 & Elettaria cardamomum, Hevea brasiliensis & India, India \\
\hline medicaginis & P10683 & Medicago sativa & United States \\
\hline megakarya & P8516 & Theobroma cacao & Sao Tome \\
\hline megasperma & P1679, P3136 & Malus sylvestris, Brassica napus var.. napus & United States, Australia \\
\hline melonis & P10994 & Trichosanthes dioica & India \\
\hline mengei & P1273, P0911 & Persea americana, Persea americana & United States, United States \\
\hline mexicana & P0646 & Solanum lycopersicum & Mexico \\
\hline mirabilis & P3005 & Mirabilis jalapa & Mexico \\
\hline multivesiculata & $\mathrm{P} 10410$ & Cymbidium & The Netherlands \\
\hline multivora & P1821, P7902, P19594 & Ocotea bullata, Pinus radiata & South Africa, United States \\
\hline nemorosa & $\mathrm{P} 10288$ & Lithocarpus densiflorus & United States \\
\hline nicotianae & $\mathrm{P} 1452$ & Citrus sp. & United States \\
\hline novaeguine & P3389 & Auracaria & New Guinea \\
\hline sp. niederhauserii & P10617 & Thuja occidentalis & United States \\
\hline pachypleura & P19986, P19987, P19988 & $\ldots$ & $\ldots$ \\
\hline palmivora & $\mathrm{P} 0255$ & Theobroma cacao & Costa Rica \\
\hline parsiana & P15164 & Ficus carica & Iran \\
\hline parvispora & P8495 & Beaucamea sp. & Germany \\
\hline phaseoli & P10145 & Phaseolus lunatus & United States \\
\hline pini & P0767, P10204 & Syringa sp., Rhododendron sp. & Canada, United States \\
\hline pinifolia & P16100 & Pinus radiata & Chile \\
\hline pistaciae & P6197 & Pistacia vera & Iran \\
\hline plurivora & P10679 & Juglans regia $\mathrm{L}$. & New Zealand \\
\hline polonica & $\mathrm{P} 15005, \mathrm{P} 19522$ & $\ldots$ & Poland \\
\hline porri & P7518 & Allium porrum & The Netherlands \\
\hline primulae & P10333 & Primula acaulis & Germany \\
\hline pseudosyringae & P10437 & Quercus robur & Germany \\
\hline pseudotsugae & P10339 & Psendotsuga menziesii & United States \\
\hline psychrophila & P10433 & Quercus robur & Germany \\
\hline quercetorum & $\mathrm{P} 15555$ & Quercus rubra rhizosphere & United States \\
\hline quercina & P10334 & Quercus robur & Germany \\
\hline quininea & P3247 & Cinchona officinalis & Peru \\
\hline ramorum & P10301 & Rhododendron sp. & The Netherlands \\
\hline richardiae & P6875 & Zantedeschia aethiopica & United States \\
\hline riparia & P19799 & $\ldots$ & $\ldots$ \\
\hline rosacearum & P3315 & Prunus persica & United States \\
\hline rubi & P3289 & Rubus sp. & United States \\
\hline sansomeana & P3163 & Silene latifolia subsp. alba & United States \\
\hline sinensis & $\mathrm{P} 1475$ & $\ldots$ & $\ldots$ \\
\hline siskiyouensis & P15122 & Seasonal tributary & United States \\
\hline sojae & P3114 & Glycine max & United States \\
\hline syringae & P10330 & Rhododendron sp. & Germany \\
\hline tentaculata & P8497 & Chrysanthemum leucanthemum & Germany \\
\hline trifolii & P7010 & Trifolium sp. & United States \\
\hline tropicalis & P10329 & Macadamia integrifolia & United States \\
\hline uliginosa & P10413 & Rhizosphere of Quercus robur & Poland \\
\hline vignae & P3019 & Vigna unguiculata & Australia \\
\hline virginiana & P19828, P19829 & $\ldots$ & $\ldots$ \\
\hline$\times$ pelgrandis & P19984 & $\ldots$ & $\ldots$ \\
\hline$\times$ serendipita & P19985 & $\ldots$ & $\ldots$ \\
\hline Pythium and Phytopythium spp. ${ }^{\mathrm{c}}$ & & $\ldots$ & $\ldots$ \\
\hline Pythium sp. & 1989-19 & $\ldots$ & $\ldots$ \\
\hline Pythium acanthicum & A-6 & $\ldots$ & $\ldots$ \\
\hline P. aphanidermatum & $1991-5$ & $\ldots$ & $\ldots$ \\
\hline \multirow[t]{2}{*}{ P. aristosporum } & 1999-19 & $\ldots$ & $\ldots$ \\
\hline & & & (continued on next page) \\
\hline
\end{tabular}


Inc.). Then, $1 \mu \mathrm{l}$ from each bag and $1 \mu \mathrm{l}$ of $P$. cactorum DNA (P0714) at $0.3 \mathrm{ng} / \mu \mathrm{l}$ was loaded into the multiplexed RPA assay described above. The buffer with the earliest onset of amplification for both the pathogen and the plant was considered the optimal buffer for tissue maceration.
Testing of RPA markers for sensitivity and specificity. To test the sensitivity of the multiplexed RPA assay, purified DNA of P. cactorum (P0714), P. cinnamomi (P2110), and P. ramorum (Prg-2) was loaded separately into a reaction at a concentration ranging from $3 \mathrm{ng}$ to $1 \mathrm{fg}$ (based on Qubit Florometer values).

TABLE 1. (continued from preceding page)

\begin{tabular}{|c|c|c|c|}
\hline Species & Isolate number ${ }^{\mathrm{a}}$ & Host species & Country \\
\hline P. arrhenomanes & 1991-9 & $\ldots$ & $\ldots$ \\
\hline P. catenulatum & $1986-8$ & $\ldots$ & $\ldots$ \\
\hline P. graminicola & $1992-13$ & $\ldots$ & $\ldots$ \\
\hline P. insidiosum & 58643 & $\ldots$ & $\ldots$ \\
\hline P. irregulare & $1987-97$ & $\ldots$ & $\ldots$ \\
\hline P. myriotylum & $1987-134$ & $\ldots$ & $\ldots$ \\
\hline P. nunn & $1987-58$ & $\ldots$ & $\ldots$ \\
\hline P. oligandrum & $\mathrm{C} 3$ & $\ldots$ & $\ldots$ \\
\hline P. paroecandrum & $1987-60$ & $\ldots$ & $\ldots$ \\
\hline P. pyrilobum & 1999-28 & $\ldots$ & $\ldots$ \\
\hline$P$. rostratum & 1986-14 & $\ldots$ & $\ldots$ \\
\hline P. spinosum & $79-4$ & $\ldots$ & $\ldots$ \\
\hline P. splendens & $85-3$ & $\ldots$ & $\ldots$ \\
\hline P. sulcatum & $1987-98$ & $\ldots$ & $\ldots$ \\
\hline P. sylvaticum & $1991-23$ & $\ldots$ & $\ldots$ \\
\hline P. ultimum (HS isolate) & $23-1$ & $\ldots$ & $\ldots$ \\
\hline P. ultimum & $1987-92$ & $\ldots$ & $\ldots$ \\
\hline P. ultimum & P2006 & Pea, cucumber & United States \\
\hline P. undulatum & P10342 & $\ldots$ & $\ldots$ \\
\hline P. vanterpoolii & 1999-31 & $\ldots$ & $\ldots$ \\
\hline Phytopythium vexans & P8419, P3980 & Solanum tuberosum & Canada \\
\hline Plant species & $\ldots$ & $\ldots$ & $\ldots$ \\
\hline Citrus sp. & $\ldots$ & $\ldots$ & United States \\
\hline Fragaria $\times$ ananassa & $\ldots$ & $\ldots$ & United States \\
\hline Umbellularia californica & $\ldots$ & $\ldots$ & United States \\
\hline Persea americana & $\ldots$ & $\ldots$ & United States \\
\hline Rhododendron sp. & $\ldots$ & $\ldots$ & United States \\
\hline Rubus sp. & $\ldots$ & $\ldots$ & United States \\
\hline
\end{tabular}

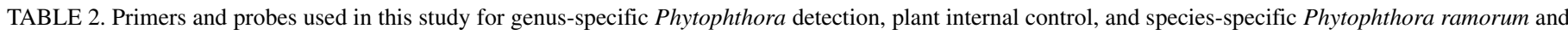
P. kernoviae detection with the TwistAmp exo and nfo kits (TwistDx Ltd., Cambridge, UK) ${ }^{\mathrm{a}}$

\begin{tabular}{|c|c|c|c|c|}
\hline Primers, probes & Sequence $\left(5^{\prime}-3^{\prime}\right)$ & $\begin{array}{l}\text { Length } \\
\text { (bp) }\end{array}$ & $\begin{array}{l}\mathrm{GC} \\
(\%)\end{array}$ & Target \\
\hline \multicolumn{5}{|l|}{ Primers } \\
\hline \multicolumn{5}{|c|}{ Phytophthora genus-specific } \\
\hline TrnM-F & ATGTAGTTTAATGGTAGAGCGTGGGAATC & 29 & 41.4 & tRNA-M \\
\hline TrnM-R & GAACCTACATCTTCAGATTATGAGCCTGATAAG & 33 & 39.4 & tRNA-M \\
\hline Atp9-F & ССТTСТTTAСАACAAGAATTAATGAGAACCGCTAT & 35 & 34.3 & ATP9 \\
\hline Nad9-nfo-R & GTAGAAATATTAATACATAATTCATTTTTRTA & 32 & 14.1 & NAD9 \\
\hline \multicolumn{5}{|l|}{ Plant internal control } \\
\hline Cox1-IPC-F & CATGCGTGGACCTGGAATGACTATGCATAGA & 31 & 48.4 & COXI \\
\hline Cox1-IPC-R & GGTTGTATTAAAGTTTCGATCGGTTAATAACA & 32 & 31.3 & COXI \\
\hline \multicolumn{5}{|c|}{ Phytophthora spp.-specific } \\
\hline Atp9Nad9-Pram-R & CAATGCATAATACAAGTCTAGACGTAACGT & 30 & 36.7 & P. ramorum ATP9-NAD9 spacer \\
\hline Atp9Nad9-Pkern-R & ATATTACAAGATATATATTTATATTATTCACAG & 33 & 15.2 & P. kernoviae ATP9-NAD9 spacer \\
\hline \multicolumn{5}{|c|}{ Nested PCR and sequencing } \\
\hline PhyG-F2 & CGTGGGAATCATAATCCT & 18 & 44.4 & tRNA-M \\
\hline PhyG-Rb & CAGATTATGAGCCTGATAAG & 20 & 40.0 & tRNA-M \\
\hline TrnM_Rseq1 & АССТАТТАСТСТАТСТСАТС & 20 & 35.0 & tRNA-M \\
\hline Nad9_Fseq1 & GCATTAACTGAAGCAATTGC & 20 & 40.0 & АТР9 \\
\hline Nad9_Rseq1 & GTAAAATTTGTAATAAATATTGACT & 25 & 16.0 & NAD9 \\
\hline \multicolumn{5}{|c|}{ 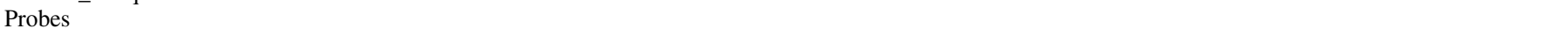 } \\
\hline \multicolumn{5}{|l|}{ Phytophthora genus } \\
\hline TrnM-P & $\begin{array}{l}\text { TAGAGCGTGGGAATCATAATCCTAATGTTG [FAM-dT] A } \\
\text { [THF] G [BHQ1-dT] TCAAATCCTACCATCAT [3'-C3SPACER] }\end{array}$ & 51 & 37.3 & tRNA-M \\
\hline \multicolumn{5}{|l|}{ Plant internal control } \\
\hline Cox1-IPC-P & $\begin{array}{l}\text { GGTCCGTTCTAGTGACAGCATTCCYACTTTTATTA [TAM- } \\
\text { dT] C [THF] C [BHQ2-dT] YCCGGTACTGGC [3'-C3SPACER] }\end{array}$ & 51 & 49.0 & COXI \\
\hline \multicolumn{5}{|c|}{$\begin{array}{l}P . \text { ramorum, } P . \text { kernoviae, and } \\
\text { nfo genus-specific }\end{array}$} \\
\hline Atp9-P & $\begin{array}{l}\text { TTGCTTTATTYTGTTTAATGATGGCWTTY [FAM-dT] T [THF] } \\
\text { A [BHQ1-dT] YTTATTTGCTTTTT [3'-C3SPACER] }\end{array}$ & 47 & 22.3 & ATP9 \\
\hline
\end{tabular}

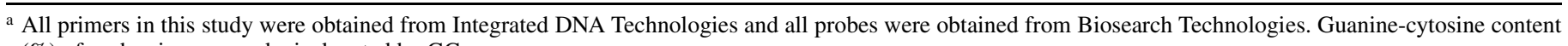
(\%) of each primer or probe is denoted by GC. 
Standard curve plots of the log of concentration and the OT were constructed based on two replicate reactions.

To compare the sensitivity of RPA technology to more conventional TaqMan real-time PCR, a serial dilution of purified DNA ( $2 \mathrm{ng}$ to $0.2 \mathrm{fg}$ ) from $P$. ramorum (Prg-2) was amplified with the Phytophthora genus-specific trnM-trnP-trnM and $P$. ramorum species-specific atp9-nad9 TaqMan assays developed by Bilodeau et al. (5). The same serial dilution was also loaded into the multiplexed Phytophthora genus-specific and P. ramorum species-specific RPA assays described above using two replicate reactions per experiment. The log of concentration was plotted against cycle threshold $(\mathrm{Ct})$ values and OT values for TaqMan and RPA assays, respectively.

In order to compare the effect of plant DNA on amplification efficiency and sensitivity, Umbellularia californica P. ramorumfree leaf tissue DNA was extracted using a DNeasy Plant Mini kit (Qiagen, Venlo, The Netherlands) following the manufacturer's recommendations and the Animal and Plant Health Inspection Service (APHIS) protocol guidelines for $P$. ramorum detection (32). Then, $2 \mu \mathrm{l}$ of this extract $(73 \mathrm{ng} / \mu \mathrm{l})$ was loaded into each tube of the $P$. ramorum serial dilution and run in the atp9-nad9 TaqMan assay of Bilodeau et al. (5). The effect of plant material on RPA was also investigated for the Phytophthora genus-specific RPA assay in pathosystems such as $P$. cactorum-Fragaria $\times$ ananassa crown tissue, $P$. cinnamomi-Persea americana root tissue, and Phytophthora ramorum-U. californica leaf tissue. Crude tissue macerations were taken from disease-free plants of the aforementioned pathosystems as previously described and $1 \mu \mathrm{l}$ of this, along with $1 \mu \mathrm{l}$ of a serial dilution of culture-purified DNA from the corresponding Phytophthora spp. (3 ng to $0.3 \mathrm{fg}$ ), was loaded into the RPA assay and the log of concentration was plotted against OT values from two replicate reactions.

To test for specificity, purified DNA from each of the isolates listed in Table $1(1 \mathrm{ng} / \mu \mathrm{l})$ was tested in the multiplexed RPA assay for Phytophthora genus-specific and plant internal control detection. To test specificity in the Phytophthora species-specific RPA assays ( $P$. ramorum and $P$. kernoviae), a bulked segregate analysis was used to save reagents. In other words, in these assays, template volumes were $5 \mu \mathrm{l}(1 \mu \mathrm{l}$ from each of five species bulked) and, if cross reactivity was detected, the assay was repeated with each species individually.

Validation of RPA assays using field samples. Samples were collected from several locations throughout California in order to validate the RPA assays with environmental samples and compare them with results from traditional isolation on media and the Phytophthora genus-specific atp9-nad9 TaqMan assay. Samples were collected from a variety of hosts (Table 3). Fresh host tissue $(0.5 \mathrm{~g})$ was ground as described above in $5 \mathrm{ml}$ of GEB2 buffer

TABLE 3. Field validation of recombinase polymerase amplification (RPA) assay for Phytophthora genus-specific and Phytophthora ramorum species-specific detection $^{\mathrm{a}}$

\begin{tabular}{|c|c|c|c|c|c|c|c|c|c|c|}
\hline Host species & Host common name & $\begin{array}{l}\text { Tissue } \\
\text { type }\end{array}$ & Pos & Origin & $\begin{array}{l}\text { Phytophthora spp. } \\
\text { identified }^{\mathrm{b}}\end{array}$ & $\begin{array}{l}\text { Phytophthora } \\
\text { genus-specific } \\
\text { RPA }\end{array}$ & $\begin{array}{c}\text { P. ramorum } \\
\text { species- } \\
\text { specific RPA }^{c}\end{array}$ & $\begin{array}{l}\text { TaqMan } \\
\text { PCR }\end{array}$ & Isolation $^{\mathrm{d}}$ & $\mathrm{Neg}^{\mathrm{e}}$ \\
\hline Agave potatorum & Agave & Root & 4 & Tulare & nicotianae & + & $\mathrm{nt}$ & + & + & 0 \\
\hline Arctostaphylos sp. & Manzanita & Leaf & 1 & $\begin{array}{l}\text { Contra Costa, } \\
\text { San Luis Obispo }\end{array}$ & sp. PgChlamydo & + & - & + & NP & 1 \\
\hline Aucuba japonica & Gold dust plant & Root & 1 & Tulare & citricola clade $\mathrm{E}$ & + & $\mathrm{nt}$ & + & + & 3 \\
\hline Capsicum sp. & Chili pepper & Root & 3 & Santa Barbara & inundata & + & $\mathrm{nt}$ & + & NS & 1 \\
\hline Ceanothus sp. & Ceanothus & Leaf & 1 & Stanislaus & palmivora & + & - & + & NP & 1 \\
\hline Citrus sp. & $\begin{array}{l}\text { Navel orange, } \\
\text { grapefruit, Valencia } \\
\text { orange, lemon }\end{array}$ & Fruit & 11 & Riverside & $\begin{array}{l}\text { citrophthora* and } \\
\text { syringae* }\end{array}$ & + & $\mathrm{nt}$ & + & + & 0 \\
\hline Citrus sp. & Grapefruit & Root & 1 & Riverside & citrophthora & + & $\mathrm{nt}$ & + & + & 15 \\
\hline Diospyros sp. & Persimmons & Root & 1 & Tulare & nicotianae & + & $\mathrm{nt}$ & + & NS & 1 \\
\hline Fragaria $\times$ ananassa & Strawberry & Crown & 6 & Ventura, Santa Barbara & cactorum* & + & $\mathrm{nt}$ & + & + & 15 \\
\hline Gardenia jasminoides & Gardenia & Root & 11 & Tulare & nicotianae & + & $\mathrm{nt}$ & + & + & 0 \\
\hline Hedera sp. & Ivy & Leaf & 1 & San Luis Obispo & tropicalis & + & - & + & NP & 0 \\
\hline Laurus nobilis & Bay laurel & Leaf & 1 & Sacramento & multivora & + & - & + & NP & 0 \\
\hline $\begin{array}{l}\text { Lavandula sp. } \\
\text { Leucophyllum }\end{array}$ & Lavender & Root & 2 & Santa Barbara & nicotianae & + & $\mathrm{nt}$ & + & + & 0 \\
\hline zygophyllum & Cimmeron & Root & 1 & Tulare & nicotianae & + & $\mathrm{nt}$ & + & NS & 2 \\
\hline Magnolia grandiflora & Magnolia & Leaf & 1 & Ventura & palmivora & + & - & + & NP & 0 \\
\hline Myrtus sp. & Myrtus & Crown & 1 & Santa Barbara & nicotianae & + & - & + & NP & 0 \\
\hline Persea americana & Avocado & Root & 4 & Santa Barbara, Riverside & $\begin{array}{l}\text { cinnamomi and } \\
\text { citrophthora }\end{array}$ & + & $\mathrm{nt}$ & + & + & 19 \\
\hline Pittosporum tenuifolium & Silver Sheen & Root & 1 & Santa Barbara & nicotianae & + & $\mathrm{nt}$ & + & NS & 2 \\
\hline Pseudotsuga menziesii & Douglas fir & Leaf & 1 & El Dorado & cambivora & + & - & + & NP & 0 \\
\hline Rhamnus californica & Coffee berry & Root & 2 & Santa Cruz & cactorum* & + & $\mathrm{nt}$ & + & + & 0 \\
\hline Rhododendron sp. & Azalea & Leaf & 2 & Los Angeles, Ventura & tropicalis & + & - & + & NP & 2 \\
\hline Rhododendron sp. & Rhododendron & Leaf & 5 & Marin & ramorum & + & + & + & + & 0 \\
\hline Rhododendron sp. & Azalea fuchsia & Root & 1 & Tulare & nicotianae* & + & $\mathrm{nt}$ & + & + & 2 \\
\hline Rhus integrifolia & Lemonade berry & Root & 1 & Santa Barbara & nicotianae & + & $\mathrm{nt}$ & + & + & 0 \\
\hline Rosmarinus officinalis & Rosemary & Root & 4 & Tulare & nicotianae & + & $\mathrm{nt}$ & + & + & 0 \\
\hline Rubus sp. & Raspberry & Crown & 8 & Santa Cruz & $r u b i^{*}$ & + & $\mathrm{nt}$ & + & + & 2 \\
\hline Rubus sp. & Raspberry & Root & 1 & San Benito & cactorum* & + & $\mathrm{nt}$ & + & + & 0 \\
\hline Syringa sp. & Lilac & Root & 1 & Tulare & nicotianae & + & $\mathrm{nt}$ & + & NS & 1 \\
\hline Umbellularia californica & Bay laurel & Leaf & 11 & Marin, Monterey, Sonoma & ramorum* & + & + & + & + & 23 \\
\hline Viburnum sp. & Viburnum & Leaf & 2 & Marin & ramorum & + & + & + & + & 3 \\
\hline
\end{tabular}

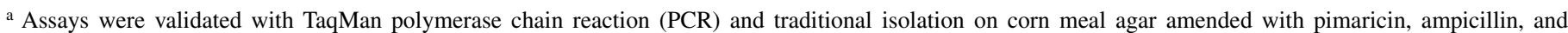

rifampicin (CMA-PAR) media. Pos = numbers of positive samples, Origin $=$ origin of samples (California county), and Neg $=$ number of negative samples.

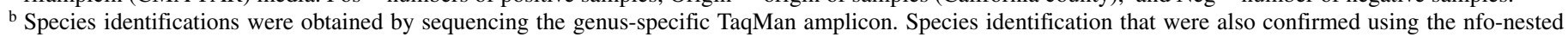
amplification protocol are denoted with an asterisk.

c Only leaf samples which tested positive for Phytophthora were tested with the species-specific P. ramorum test; nt = samples that were not tested.

${ }^{\mathrm{d}} \mathrm{NP}=$ not possible and NS = No significant Pythium spp. present.

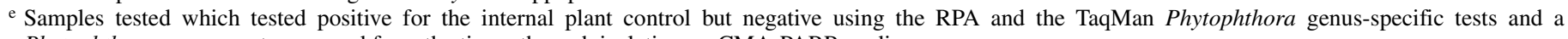

Phytophthora sp. was not recovered from the tissue through isolation on CMA-PARP media. 
and tested using the multiplexed RPA assay for Phytophthora genus-specific and plant internal control detection. DNA was then extracted from this crude extract using the DNeasy Plant Mini kit (Qiagen) starting at step 7 and following the manufacturer's protocols. TaqMan amplification reactions of the atp9-nad9 locus were then performed as outlined by Bilodeau et al. (5) and amplicons were sequenced with the NAD9-F primer (5'-TACA ACAAGAATTAATGAGAAC-3') to confirm identification of the species present. For species identification, a local BLAST was performed using the BioEdit Sequence Alignment Editor v7.2.5 (Ibis Biosciences, Carlsbad, CA) against our sequence database for these loci (Supplemental Files 1 and 2). For traditional isolation, five separate $1-\mathrm{cm}$ tissue sections were rinsed in sterile deionized water, blotted dry on sterile paper towels, and placed on corn meal agar amended with pimaricin at $5 \mu \mathrm{g} / \mathrm{ml}$, ampicillin at $250 \mu \mathrm{g} / \mathrm{ml}$, and rifampicin at $10 \mu \mathrm{g} / \mathrm{ml}$ (18). Cultures were incubated at $22^{\circ} \mathrm{C}$ in the dark for 3 to 7 days. Isolates were then transferred to V8 solid agar media (200 ml of V8 juice, $2 \mathrm{~g}$ of $\mathrm{CaCO}_{3}$, and $15 \mathrm{~g}$ of agar per liter) and identified by morphology.

Technologies to confirm a positive RPA reaction. To confirm a positive detection and determine the species present by sequencing, two different techniques were developed. To verify if a Phytophthora sp. was present from a positive Phytophthora genus-specific RPA detection (trnM-trnP-trnM locus), samples were removed after $25 \mathrm{~min}$ of amplification and incubated at $95^{\circ} \mathrm{C}$ for 5 min to deactivate enzymes present in RPA, and a 10 -fold dilution of the products was created. Afterward, a nested PCR reaction was performed containing $1 \mu$ of the dilution from the RPA, $2 \mathrm{mM} \mathrm{MgCl} 2,400 \mathrm{nM}$ genus-specific PCR primers PhyG-F2 and PhyG-Rb, and standard PCR reagents (5). The amplification protocol included an initial denaturization step at $94^{\circ} \mathrm{C}$ for $2 \mathrm{~min}$, followed by 35 cycles at $94^{\circ} \mathrm{C}$ for $30 \mathrm{~s}, 55^{\circ} \mathrm{C}$ for $30 \mathrm{~s}$, and $72^{\circ} \mathrm{C}$ for $30 \mathrm{~s}$. The reaction was completed by a $10-\mathrm{min}$ extension at $72^{\circ} \mathrm{C}$. PCR products were separated on a $1.5 \%$ agarose Tris-borate-EDTA gel to confirm amplification. Amplicons were then sequenced with PhyG-F2 and TrnM_Rseq1.

To confirm which Phytophthora sp. was present after a positive RPA detection, a forward primer (Atp9-F), probe (Atp9-P), and reverse primer (Nad9-nfo-R) were used to amplify the atp-nad9 locus using the TwistAmp nfo kit (Twistdx). This kit uses chemistry similar to that of the TwistAmp exo kit but does not utilize an exonuclease that degrades the template, and the reaction occurs at a slower rate. The reaction was carried out under the following conditions (primers and probes were all at a concentration of $10 \mu \mathrm{M}$ ): $2.1 \mu \mathrm{l}$ of Atp9-F, $2.1 \mu \mathrm{l}$ of Nad9-nfo-R, $0.9 \mu \mathrm{l}$ of Atp9-P, $29.5 \mu \mathrm{l}$ of rehydration buffer, $11.9 \mu \mathrm{l}$ of DNase-free water, $1 \mu \mathrm{l}$ of template, and $2.5 \mu \mathrm{l}$ of $280 \mathrm{mM}$ magnesium acetate. Samples were removed after 35 min of amplification and incubated at $95^{\circ} \mathrm{C}$ for $5 \mathrm{~min}$ to deactivate enzymes present in RPA reactions, and a 10 -fold dilution of the products was created. A nested PCR reaction was then performed containing $1 \mu$ of the dilution from the RPA, $2 \mathrm{mM} \mathrm{MgCl} 2,400 \mathrm{nM}$ primers Nad9_Fseq1 and Nad9_Rseq1, and standard PCR reagents. The amplification protocol and PCR product visualization was the same as described above and the amplicon was sequenced with amplification primers.

Detection equipment. Three different devices were tested for their use with the TwistAmp exo kits: the Twista portable realtime fluorimeter (Twistdx), SMART-Dart Bluetooth-enabled device (Diagenetix, Inc., Honolulu, HI), and CFX96 Real-Time PCR Detection System (Bio-Rad Laboratories, Hercules, CA). In order to run RPA assays in the SMART-Dart and CFX96 RealTime PCR machines, the protocols needed to be modified; therefore, the reaction was incubated at $39^{\circ} \mathrm{C}$, data were collected every $20 \mathrm{~s}$ for a period of $30 \mathrm{~min}$, and the agitation step $5 \mathrm{~min}$ after initiating amplification was removed because of the inability to pause data collection in this unit. For the CFX96 Real-Time PCR Detection System, data were shown in terms of cycles because, whereas the run was developed to take $20 \mathrm{~min}$, the actual run was $\approx 32$ min because of extra time spent during data collection.

\section{RESULTS}

Sensitivity of Phytophthora RPA assays. Mitochondrial gene order differences between Phytophthora and Pythium or plant spp. allowed for the development of a highly specific marker system using the RPA technology in the trnM-trnP-trnM and atp9-nad9 regions of Phytophthora spp. (Fig. 1). The Phytophthora genus-specific (Fig. 2A) and P. ramorum (Fig. 2C) speciesspecific assays were able to detect purified DNA of $P$. ramorum at a concentration of $200 \mathrm{fg}$, with detection not observed below this threshold (Fig. 2). The onset of amplification for both the Phytophthora genus-specific and the $P$. ramorum species-specific RPA assays occurred between 6 and $17 \mathrm{~min}$, depending on initial DNA concentration (Fig. 2B). The lower concentration of $200 \mathrm{fg}$ was detectable but overall FAM fluorescence was low (Fig. 2A and C). Sensitivity and fluorescence measurements of the $P$. kernoviae species-specific assay were similar to results observed with the P. ramorum species-specific assay (Fig. 3).

The onset of amplification as it related to the log of DNA concentration was not linear in RPA assays (Fig. 2B). Therefore, the initial 5-min preagitation step was subtracted from the data, and the data were log transformed. This log-transformed value, termed the OT, was plotted against concentration, and the Phytophthora genus-specific and the $P$. ramorum and $P$. kernoviae species-specific assays had a linear relationship with concentration, with $R^{2}$ values of $0.993,0.978$, and 0.954 , respectively (Fig. 2D).

Specificity of Phytophthora RPA assays. The specificity of the Phytophthora genus and species-specific RPA assays was evaluated on a wide range of Phytophthora, Pythium, and plant species (Table 1). For the Phytophthora genus-specific assay, the onset of amplification for all Phytophthora spp. tested was between 6 and $11 \mathrm{~min}$ using an initial concentration of $1 \mathrm{ng}$ of DNA. Pythium and plant species showed no cross reactivity with the assay. For the $P$. ramorum and $P$. kernoviae species-specific assays, detection occurred at 6.3 and 6 min respectively, and did not cross-react with any other Phytophthora spp. at the concentration tested (1 ng DNA). Additionally, no Pythium or plant species showed cross reactivity with these species-specific assays.

TaqMan PCR versus RPA assays and the effect of extraction buffers and plant DNA on detection. Extraction buffers tested for their ability to crudely extract DNA from Fragaria $\times$ ananassa crown tissue had an effect on the onset of amplification of the plant internal control and P. cactorum detection. Buffer GEB2 and all three ELISA grinding buffers at $\mathrm{pH}$ 8.0, 9.5, and 11.0 were able to provide amplifiable Fragaria $\times$ ananassa DNA, and the onset of amplification values were 7.0, 7.0, 7.3, and 8.0 min, respectively. Likewise, these same buffers had limited effect on amplification of $P$. cactorum-purified DNA that was spiked into the crude Fragaria $\times$ ananassa DNA extractions, and the onset of amplification values were 6.3, 6.7, 7.0, and $7.0 \mathrm{~min}$, respectively. Plant and $P$. cactorum templates were not amplified when using the extraction buffer GEB3 and the PEG buffer described above (data not shown). Due to the success and ease of use of the GEB2 buffer, all subsequent crude plant extractions utilized this buffer.

TaqMan PCR and RPA assays had similar limits of detection. The Phytophthora genus-specific (targeting trnM-trnP-trnM) and Phytophthora species-specific (targeting atp9-nad9) TaqMan assays were able to detect purified $P$. ramorum DNA at an initial quantity of $200 \mathrm{fg}$ and detection remained linear at increasing concentrations using $\mathrm{Ct}$ values $\left(R^{2}=0.997\right.$ and 0.996 , respectively) (Fig. 4A and B). The Phytophthora genus-specific (targeting trnM-trnP-trnM) and Phytophthora species-specific (targeting 
atp9-nad9) RPA assays were also able to detect purified $P$. ramorum DNA at an initial quantity of $200 \mathrm{fg}$ and detection remained linear at increasing concentrations using the OT values $\left(R^{2}=0.980\right.$ and 0.974 , respectively) (Fig. 4C and D).
Plant extract had a limited effect on both TaqMan and RPA amplification. For TaqMan assays, the standard APHIS-P. ramorum DNA extraction protocol for genus- and species-specific detection was tested with healthy $U$. californica samples spiked with a
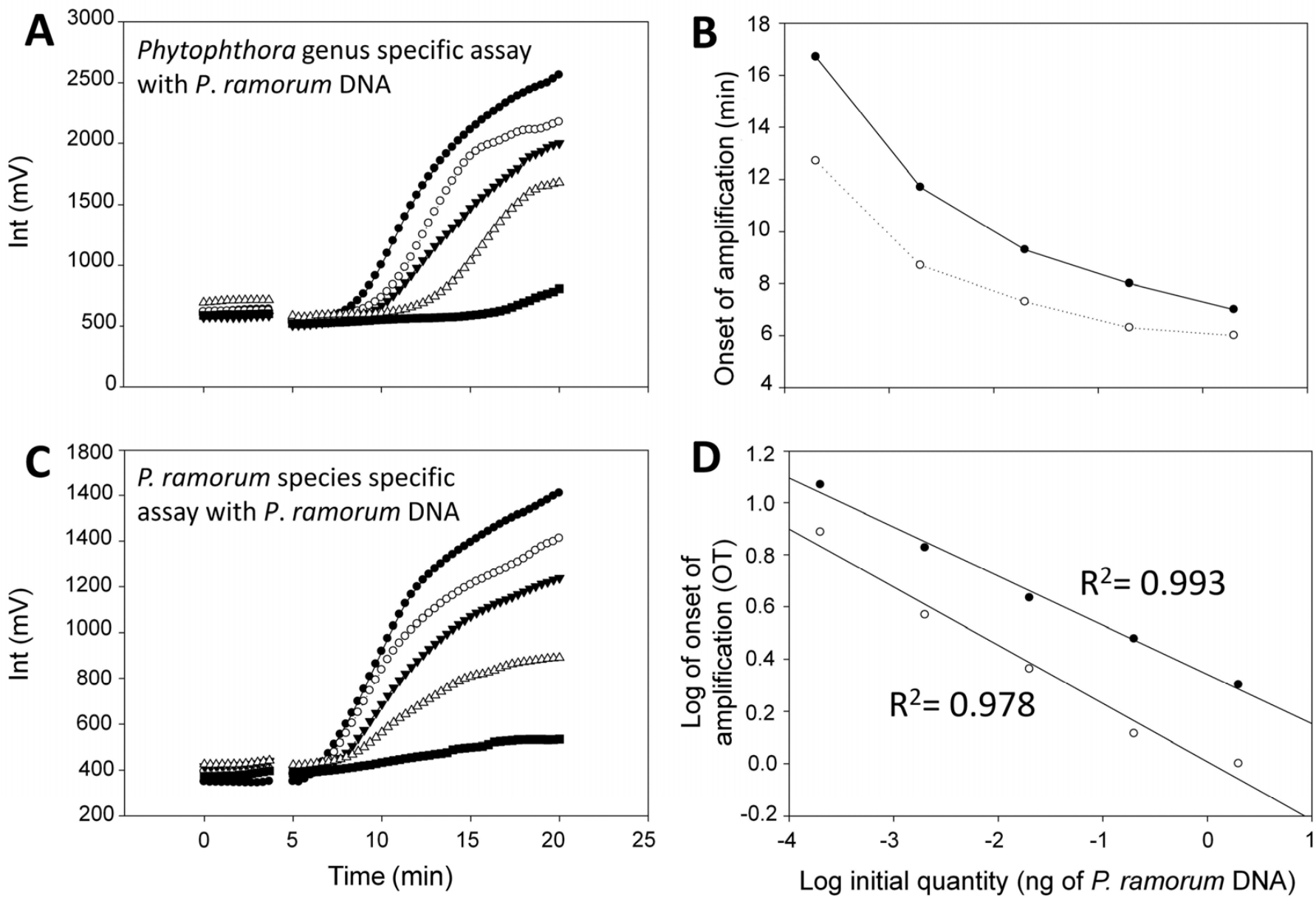

Fig. 2. Serial dilution of purified DNA of Phytophthora ramorum and standard curve plots of concentration using two different recombinase polymerase amplification (RPA) assays. A, Phytophthora genus-specific assay and C, P. ramorum species-specific assay, ranging from $2 \mathrm{ng}$ to $200 \mathrm{fg}$. B, Log of the initial DNA quantity of $P$. ramorum against the onset of amplification, where the Phytophthora genus-specific assay and $P$. ramorum species-specific assays are denoted by closed and open circles, respectively. D, Log of the initial DNA quantity of $P$. ramorum against the $\log$ of the onset of amplification minus the agitation step (OT), where the Phytophthora genus-specific assay and P. ramorum species-specific assay are denoted by closed and open circles, respectively.
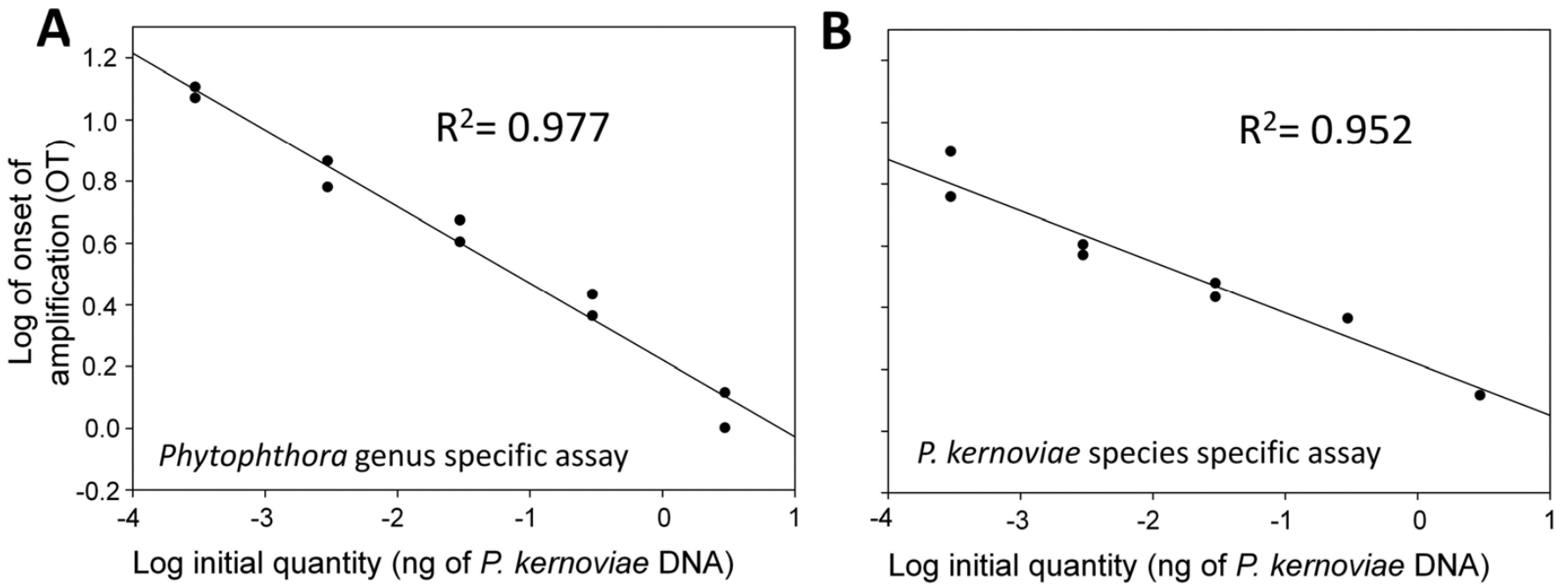

Fig. 3. Serial dilution of purified DNA of Phytophthora kernoviae and standard curve plots of the $\log$ of initial DNA concentration and the log of the onset of amplification using two different recombinase polymerase amplification assays. A, Phytophthora genus-specific assay and B, P. kernoviae species-specific assay, ranging from $3 \mathrm{ng}$ to $300 \mathrm{fg}$ of purified $P$. kernoviae DNA. 
serial dilution of purified DNA of $P$. ramorum. The addition of plant DNA to the pathogen dilution series had an effect on $P$. ramorum detection, increasing the $\mathrm{Ct}$ value between 1 and 2 across the various dilutions (Fig. 4A and B). However, P. ramorum detection still occurred at all concentrations in both the genusand species-specific assays and remained linear $\left(R^{2}=0.974\right.$ and 0.995 , respectively), albeit with a shifted time frame. Similarly, for RPA assays, the crude DNA extractions from healthy $U$. californica samples spiked with a serial dilution of purified DNA of $P$. ramorum were tested with the Phytophthora genus- and $P$. ramorum species-specific RPA assays. Addition of plant DNA to the $P$. ramorum dilution series had a limited effect on pathogen detection, delaying the onset of amplification across the dilutions, with a greater affect observed for the lowest concentrations (Fig. $4 \mathrm{C}$ and D). However, P. ramorum detection still occurred at all concentrations in both the genus- and species-specific assays and remained linear $\left(R^{2}=0.978\right.$ and 0.986 , respectively $)$, albeit with a shifted time frame. A similar effect of the plant extract was observed with the Phytophthora genus-specific assay using $P$. cactorum and $P$. cinnamomi spiked into crude plant extracts of Fragaria $\times$ ananassa crown tissue and Persea americana root tissue, respectively (Fig. 5). However, the sensitivity of Phytophthora cinnamomi detection was reduced to $3 \mathrm{pg}$ with the addition of macerated Persea americana root tissue.

Field validation of RPA assays on a variety of plant samples. RPA assays were validated using traditional culturing and conven- tional DNA extraction followed by TaqMan detection and sequencing. Of the 222 symptomatic plant samples (roots, leaves, fruit, or crowns), 91 samples tested positive with the Phytophthora genus-specific RPA assay and the TaqMan genus-specific atp9-nad9 assay (Table 3). By sequencing the TaqMan amplicon, a variety of species were identified in the field validation, including Phytophthora sp. PgChlamydo, P. cactorum, P. cambivora, $P$. cinnamomi, $P$. citricola clade E, $P$. citrophthora, $P$. inundata, $P$. multivora, $P$. nicotianae, $P$. palmivora, $P$. ramorum, $P$. rubi, $P$. syringae, and $P$. tropicalis. Of those 91 samples positive for a Phytophthora sp. using molecular techniques, only 56 yielded a Phytophthora culture when plated out with many samples heavily infected with Pythium spp. For the P. ramorum speciesspecific RPA assay, 44 plant samples were tested using this species-specific assay and 18 were positive and confirmed to be $P$. ramorum through sequencing. Of those 18 samples, $P$. ramorum was cultured from only 6.

In addition to the plant species listed in Table 3, samples were also assayed from Acanthus mollis, Anigozanthos manglesii, Asparagus officinalis, Betula sp., Bougainvillea sp., Cistus sp., Coleonema sp., Cucurbita sp., Cycas revoluta, Cynara cardunculus, Fatsia japonica, Fraxinus sp., Leucophyllum langmaniae, Ligustrum sp., Loropetalum sp., Notholithocarpus densiflorus, Phaseolus vulgaris, Prunus avium, Pseudotsuga menziesii, Trachelospermum jasminoides, Vicia faba, and Westringia fruticosa. Phytophthora spp. were not cultured from these plants and all
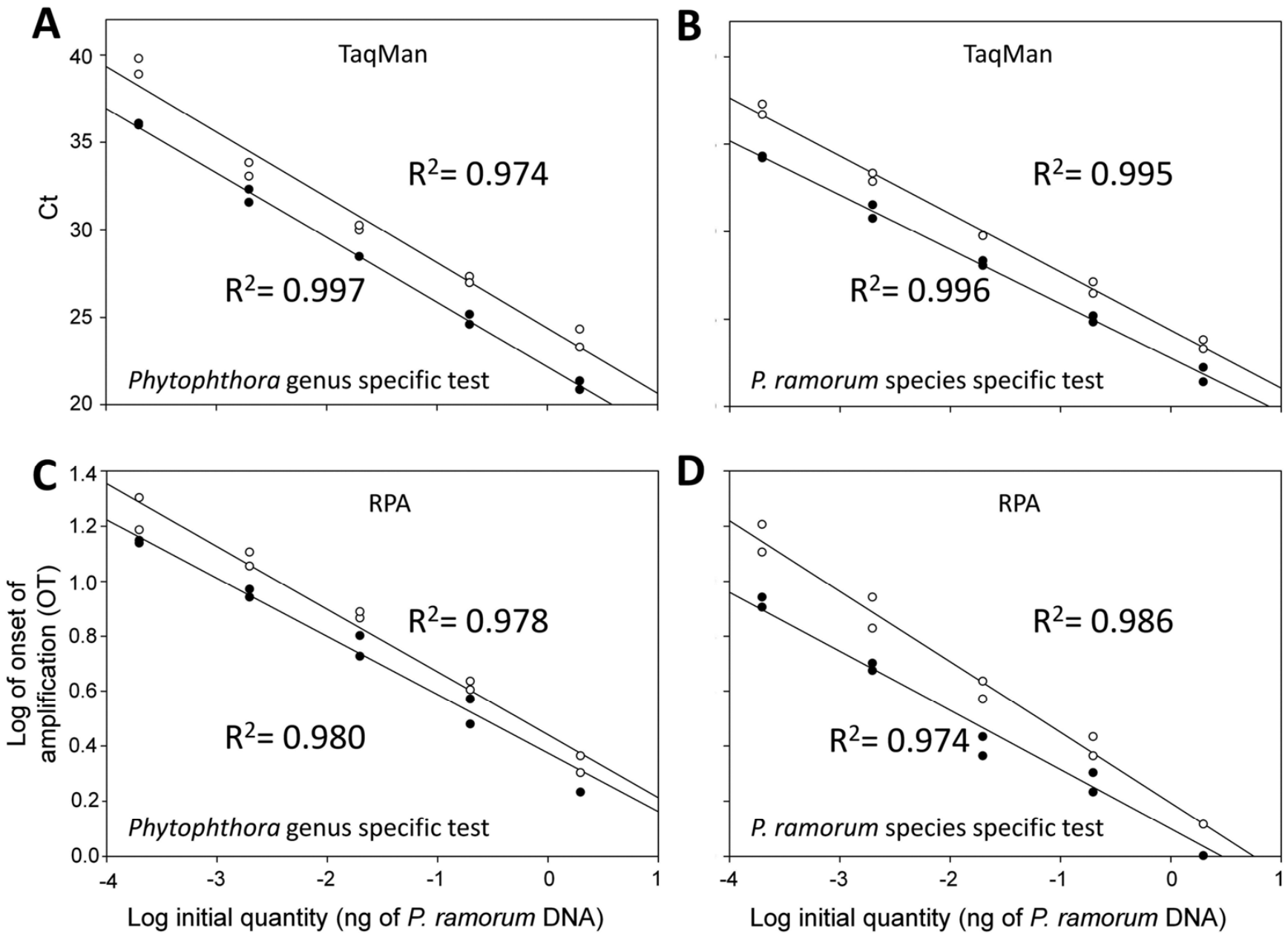

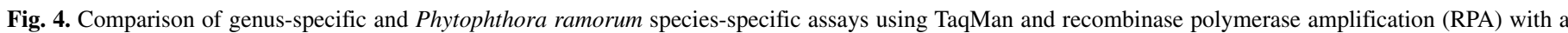

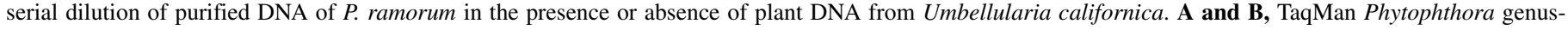

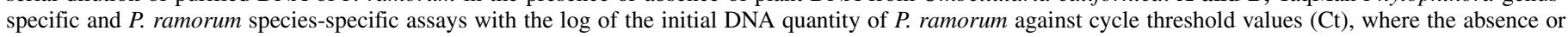

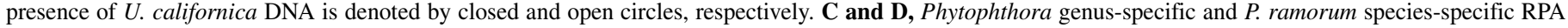

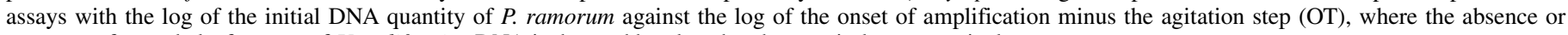
presence of a crude leaf extract of $U$. californica DNA is denoted by closed and open circles, respectively. 
were negative for this pathogen with both the TaqMan and RPA diagnostic assays. The Phytophthora RPA assays did not generate any false positives from plant or Pythium DNA from these samples.

Nested PCR and sequencing is an effective way to confirm a positive RPA product and identify the species present. A technique to confirm a positive result in an RPA assay and identify which species was present was developed using nested PCR and sequencing. This was tested against 10 samples which were found to be positive for Phytophthora spp. in our earlier field validation experiments (Table 3). Initial experiments showed that a nested PCR amplification using the trnM-trnP-trnM TwistAmp exo amplicon as a target was able to generate a template capable of being sequenced. Due to the low level of interspecific polymorphisms observed for this locus, it was difficult in many cases to confirm which species was present; however, the sequence information could easily discern between a Phytophthora or Pythium $\mathrm{sp}$. in the event that there was a mispriming because of significant variation in the first spacer region of trnM-trnP (Supplemental Figure 1). Interestingly, a ladder-type banding pattern was observed with this technique when amplified products were separated by gel electrophoresis (data not shown).

In order to identify the species that gave a positive detection in the genus-specific RPA assay, an alternative approach using the atp9-nad9 locus was developed. Although RPA amplification with primers and probe was observed, it was not possible to generate a PCR-amplifiable template using the TwistDx exo kit (data not shown). Another RPA amplification technique (TwistDx nfo kit) was tested that does not have exonuclease activity. Template amplification was fluorometrically detected and a 1:10 dilution of the amplified template was successfully amplified by nested PCR. DNA sequence data from this template confirmed the species identification of the isolate that was detected (Table 3).

RPA assay detection can be read on different assay platforms. All three machines tested (Twista, SMART-Dart, and CFX96) can be used with the RPA technology using the TwistAmp exo kits. The Twista unit was simpler to use with the technology and gave the most accurate results in terms of the time of the onset of amplification and the overall reduced background noise level and uniformity of the data (Fig. 6A). The assay also worked well in the SMART-Dart unit with a similar time frame of amplification, although the amplification curve was not as uniform as the Twista unit (Fig. 6B). The Bio-Rad CFX96 also worked well for data collection and generated a uniform amplification curve; however, because the data are collected by a cassette of sensors moving across the top of the tubes, the 20 -s cycle for data collection means the machine is in an almost continuous data collection mode (Fig. 6C).
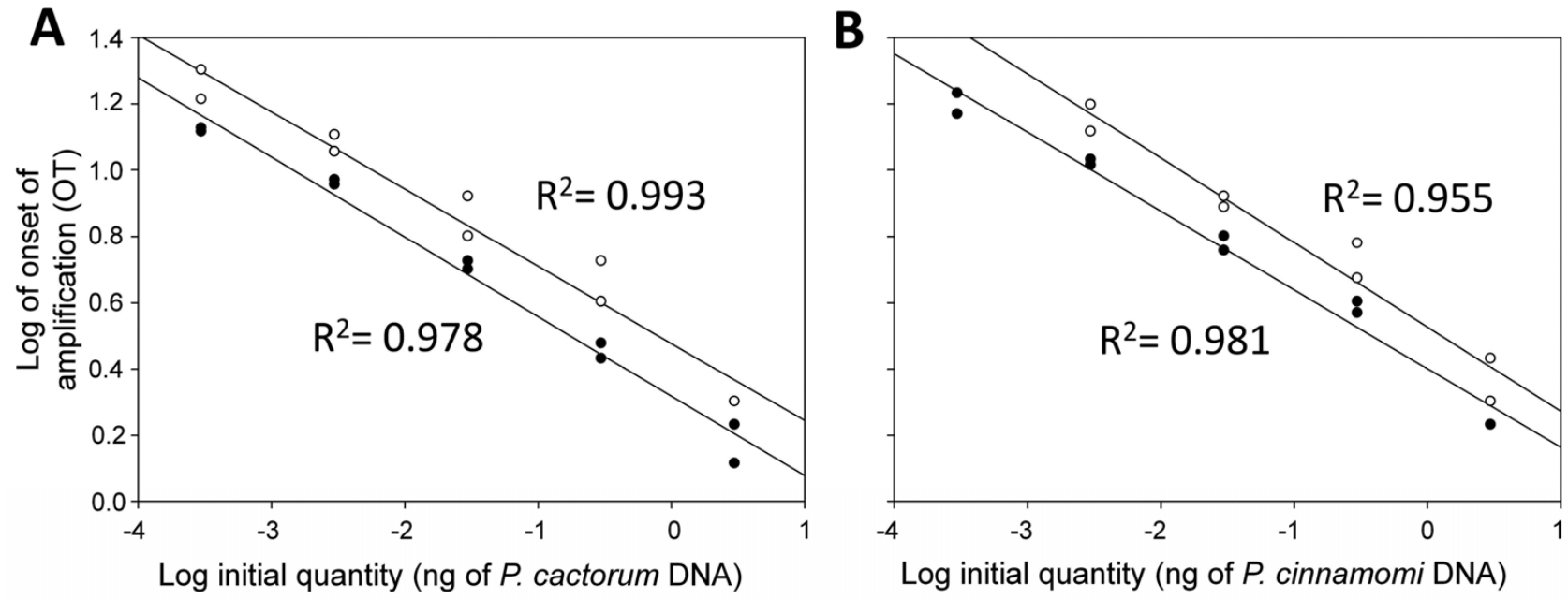

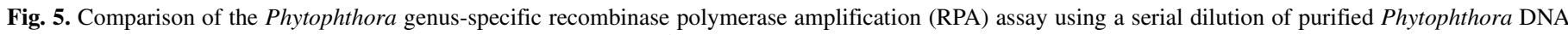

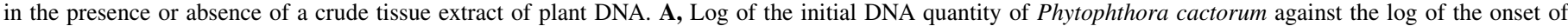

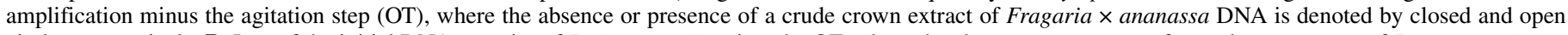

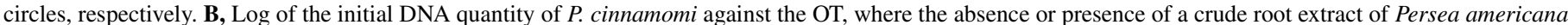
DNA is denoted by closed and open circles, respectively.
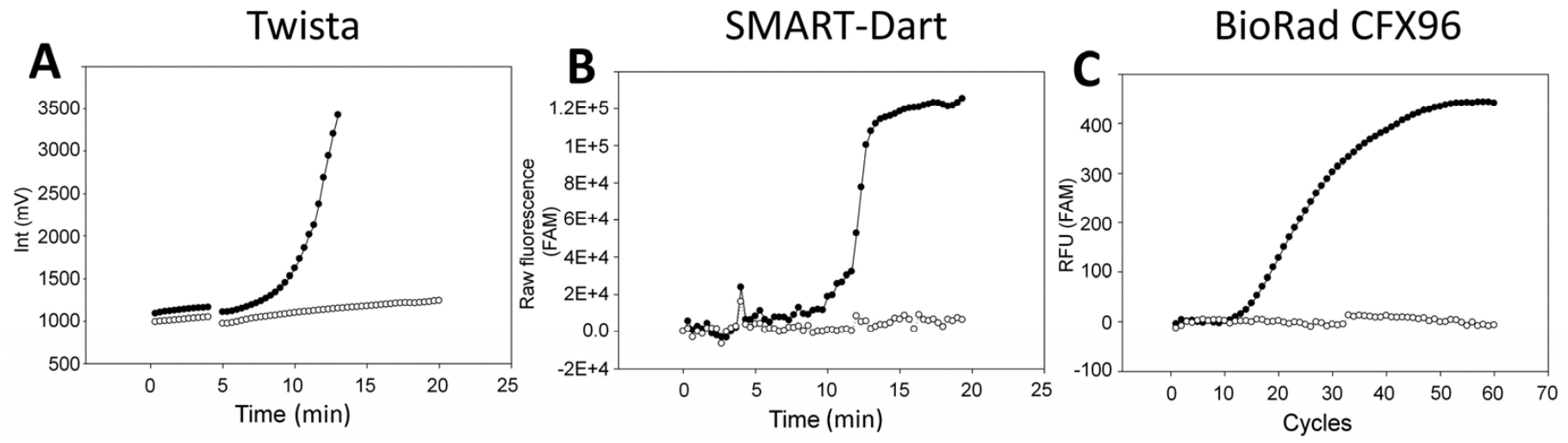

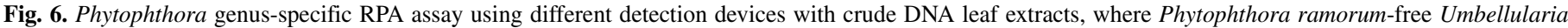

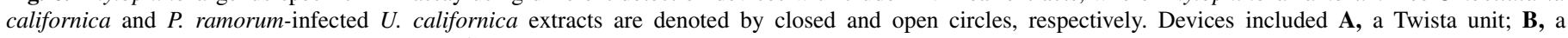
Bluetooth-enabled-SMART-Dart machine; and C, a Bio-RadCFX96 PCR machine. 


\section{DISCUSSION}

The development of a rapid isothermal molecular assay that does not require DNA extraction and is capable of detecting Phytophthora at both a genus- and species-specific level would enhance the diagnostic capabilities for this pathogen and would perhaps bring us one step closer to having a specific and sensitive detection technology that could be used directly in the field. This, in turn, would improve disease management decision-making and monitoring of pathogen spread (especially important for quarantine species). The ability to detect the pathogen at the genus level and identify the species present by sequence analysis would be an important component of this diagnostic capability because it would allow the assay to focus on a broader level than just an individual species, a feature that would be very useful when conducting pathogen surveys. The RPA isothermal assays described herein provide a technique that should help address these goals.

The assays are based on two loci spanning mitochondrial gene order differences between Phytophthora spp. and other related organisms (Pythium, Phytopythium, and plant species), thereby enhancing specificity. The genus-specific marker at the trnMtrnP-trnM locus was able to detect all Phytophthora spp. tested but did not cross react with any Pythium, Phytopythium, or plant species evaluated. These results paralleled what was observed with the TaqMan assay for this locus (5). In Pythium and Phytopythium spp., the trnM-trnP gene order is conserved but the final trnM is at least $10 \mathrm{~kb}$ away and in the opposite orientation (F. Martin, unpublished data); therefore, even if mispriming occurred, template amplification under the reaction conditions used would not take place and sequence analysis afterward would not be possible. The species-specific RPA markers that were developed based on the atp9-nad9 spacer locus were also highly specific and did not amplify plants or Pythium, Phytopythium, or other Phytophthora spp. This same locus was also used for development of a TaqMan real-time PCR assay for genus- and species-specific detection of Phytophthora (5) with the amplification primers in the atp 9 and nad 9 genes and the species-specific TaqMan probe designed from the intervening spacer region. In Pythium and Phytopythium spp., these genes are 18 to $30 \mathrm{~kb}$ apart (F. Martin, unpublished data) and cannot be amplified in the event of mispriming. With the RPA assay, the forward primer and probe are located in a conserved portion of the atp 9 gene and the reverse primer, which confers species specificity, is located in the spacer region. Given the level of interspecific polymorphisms observed in the spacer sequences and success in developing speciesspecific TaqMan probes from this region (5) (T. Miles and F. Martin, unpublished data), using this approach allows for a more systematic development of other species-specific RPA assays. Based on sequence alignments of this region, it should be possible to develop species-specific primers for this RPA assay for a wide range of Phytophthora spp. (Supplemental Figure 2).

Sensitivity of the RPA assay was similar to traditional TaqMan assays using the same locus as a target. Using culture-purified DNA as a template, genus-specific detection using the trnM-trnPtrnM locus was linear in both assays down to $200 \mathrm{fg}$. Although the addition of $U$. californica DNA (purified by standard techniques for the TaqMan assay and a crude tissue maceration for the RPA assay) reduced amplification efficiency and caused a limited delay in amplification, this did not affect the final level of sensitivity of either assay. Similar results were observed for TaqMan and RPA species-specific detection using the atp9-nad9 locus; sensitivity of detection to $200 \mathrm{fg}$ was observed for both. However, for the RPA assay, this may be a function of the host tissue examined. Although there was a reduction in sensitivity of detection of Phytophthora cinnamomi in the presence of macerated avocado root tissue $(3 \mathrm{pg})$ this was not observed for detection of $P$. cactorum when macerated strawberry crown tissue was added to the amplification (300-fg sensitivity). It should be noted that there appeared to be a high level of polysaccharides present in avocado root tissue, leading to a more viscous solution that was added to the amplification mixture; dilution of this sample may reduce this inhibition of amplification but will, in turn, dilute pathogen DNA and may reduce the sensitivity of detection. The level of sensitivity we observed with RPA was similar but not as sensitive as the TaqMan marker system reported by Bilodeau et al. (5), where the linear limit of detection was observed to be $100 \mathrm{fg}$ in most cases. However, the RPA's level of detection is more sensitive than some LAMP detection assays that have been reported for $P$. kernoviae and $P$. sojae, where the authors found the limit of detection using purified DNA to be 17 and $10 \mathrm{pg}$, respectively (12,30). However, a recent study by Chen et al. (9) has developed a LAMP detection assay for P. melonis based on the $y t p l$ gene that is sensitive down to $10 \mathrm{fg}$. These differences could be due to the copy number of the locus being targeted and the complexity in designing primers for LAMP assays.

The ability to confirm a positive in the RPA assay by template sequencing is a valuable tool, particularly when working with a genus-specific assay because this will allow for a broader analysis of the taxa present rather than detection of just a particular species. The described RPA assays provide two means for accomplishing this. If confirmation is needed only at a genus level so that the appropriate control measures for Phytophthora spp. can be initiated, then sequencing of the trnM-trnP-trnM TwistAmp exo amplicon will confirm whether a Phytophthora sp. is present versus other potential oomycete genera. The drawback of this locus is that its relatively small polymorphic trnM-trnP spacer limits the number of Phytophthora spp. that can be identified. From a research and regulatory perspective, it can be important to identify an RPA positive to a species level; for this purpose, a new set of primers and probe was designed to amplify the entire spacer region and flanking coding regions of the atp9-nad9 locus. Unlike the trnM-trnP-trnM locus, nested PCR amplification of the TwistAmp exo product from the atp9-nad9 locus was not successful in generating a sequencing template (likely due to the exonuclease activity in the amplification digesting the primer annealing sites needed for amplification of the entire amplicon); therefore, a second template amplification of the atp9-nad9 locus was done using a TwistAmp nfo kit (similar to the exo kit but does not have exonuclease activity degrading the amplified template). Although this technology is not as robust or sensitive as the TwistAmp exo kit, it did provide a template that could be PCR-amplified and sequenced without the need for DNA extraction. BLAST analysis of the sequence to a sequence database for this locus provided the species identification (Supplemental Files 1 and 2). However, because these markers are genus-specific if more than one species of Phytophthora is present, cloning would be required to get clean sequence reads.

Primer and probe design for RPA assays is very similar to conventional PCR but requires greater length. Amplification primer design is straightforward; however, to optimize specificity, it may be necessary to evaluate several primers. For example, it took only one primer validation to find the reverse primer conferring specificity for $P$. ramorum; however, for $P$. kernoviae, 15 reverse primers were evaluated before a sensitive and specific assay was developed. Among those 15 primers were 2 with locked nucleic acid (LNA) primers, 1 with a single modification at the $3^{\prime}$ end, and 1 with a modification $1 \mathrm{bp}$ in from the $3^{\prime}$ end; neither of these primers showed significant increases in specificity. Although it is not entirely clear why the final primers that were chosen were more specific, we did find that, in general, a mixture of bases at the $3^{\prime}$ end was the most effective and LNAs at the locations chosen had no effect on specificity. More research is required to better characterize the requirements for optimal primer design. Although this technology does require optimization, the 
ability to transfer existing PCR technology to an isothermal platform like RPA is a huge advantage over other techniques such as LAMP, where primer design can be complex, requires specific software to design assays, and use of AT-rich targets such as mitochondrial DNA can complicate LAMP assay design.

Another approach that was used to optimize specificity was altering the amplification primer concentrations. To achieve the greatest sensitivity, the manufacturer recommended that a total of 0.84 micromoles of primers be used, with an equal amount for the forward and reverse primers. However, early in the research, it was noticed that reducing the concentration of the conserved forward primer with a corresponding increase in the concentration of the reverse primer improved specificity. This technique was particularly important in our assays because the reverse primer provided the species specificity of the assay. The ability to focus on design of species-specific reverse primers while using a conserved forward primer and probe reduces the cost of development of additional species-specific assays because the labeled probe does not need to be redesigned.

One significant advantage of the RPA isothermal assay over PCR-based diagnostic assays is that there is no need for DNA extraction; a simple and rapid tissue maceration step was all that was needed to provide template DNA for amplification. This represents a meaningful savings in time and expense and, rather than having to run the assay in a laboratory setting, facilitates the field deployment of the technology. Because commercially available buffers commonly used for ELISA work well in the RPA assay, it is possible to follow up a positive ELISA assay with the RPA assay for confirming presence of a Phytophthora sp. using the same macerated tissue. One potential utility of RPA technology is to test soil samples. A sensitive and specific LAMP assay was recently developed for plant and soil samples of the soilborne banana pathogen Fusarium oxysporum f. sp. cubense (35). However, for soil samples, a full DNA extraction was done prior to running the LAMP assay. This would not be possible in a field situation; however, using the types of RPA assays which are tolerant of inhibitors may improve the detection capability from soil over standard TaqMan assays. Future research on rapid DNA extraction from soil in the field would aid in the utility of these isothermal technologies (either LAMP or RPA).

With a level of sensitivity similar to that of a TaqMan assay using the same loci as targets and the ability to amplify template from crude tissue macerations, the described RPA assays for Phytophthora spp. are ideally suited for use directly in the field. The Twista unit used to monitor amplification can be used with an optional battery pack for this purpose but needs to be connected to a computer in order to see the actual amplification curve (without the computer the unit will give a \pm result). Although it was originally developed for use with LAMP assays, the software in the SMART-Dart unit can adjusted to run the RPA assays and, in laboratory tests, the unit generated data that were comparable with the Twista unit. Advantages of this system are its portability (about 25\% the size of the Twista unit) and the ability to run the system and monitor amplification with an app on a smart phone connected to the unit via a Bluetooth connection. The SMART Dart system is still in development but the beta version we were working with has been used successfully directly in the field. Efforts are underway with the company to add features to improve compatibility of the unit with RPA assays.

Although using mitochondrial sequences for diagnostic assays has the advantage that the target is present in a high copy number, thereby allowing for increased sensitivity, it is important to remember that there is only one type of mitochondrial DNA present in an isolate. If a hybrid species is the target, the use of a mitochondrial marker alone may not detect the hybrid nature of the isolate (although a species-specific TaqMan real-time PCR assay has been developed for $P$. alni) (5). Although not common, hybrid species of Phytophthora do exist (23). Furthermore, if several species are expected in a particular sample, as has been reported in natural ecosystems of Australia and South Africa $(16,20,26)$, more conventional approaches (e.g., isolation) to detect Phytophthora spp. may be needed in conjunction with these RPA techniques.

The use of the RPA assay directly in the field requires some adjustments in the amplification procedure. Rather than using a portable microfuge to pellet the amplification mixture to the bottom of the tube, this can be accomplished by tapping the tubes on a hard surface or by a sharp rotating hand motion. To ensure optimum sensitivity, the manufacturer of the TwistAmp exo kit recommends remixing the tubes 4 min after initiating amplification to evenly distribute RPA amplicons in the amplification mixture. Amplification can still occur if this mixing step is omitted; however, the sensitivity of detection will be reduced (data not shown). Recently, the company that developed the TwistAmp kits (TwistDx) has released a new fluorimeter for data collection (model T-16) that eliminates this need for mixing; a single ball bearing is added to the microfuge tube in which the assays are run and a magnetic mixer in the unit ensures an even mixing during amplification.

The described RPA techniques should have a significant impact on our ability to rapidly detect Phytophthora spp. directly in the field and make management decisions immediately. Also, due to the fact that PCR technologies can be easily transferred to the RPA platform, it is possible that new assays for other species or taxa of plant pathogens could be quickly developed. We have already demonstrated an ability to make species-specific RPA assays by taking advantage of a TaqMan marker system that was developed targeting a polymorphic spacer region present in Phytophthora spp. Furthermore, making these assays genus specific will facilitate development of an array type of detection capability so that new pathogens that have been previously undetected could be identified.

\section{ACKNOWLEDGMENTS}

We thank the California Department of Food and Agriculture 2012 Specialty Crop Block Grant Program (SCB12051), the California Avocado Commission, and United States Department of Agriculture APHIS-PPQ-CPHST for funding; J. Adaskaveg and H. Förster (University of California-Riverside), C. Bloomquist (California Department of Food and Agriculture), S. Koike and M. Bolda (University of California Cooperative Extension), H. Scheck (Santa Barbara County Ag Commissioner), and K. Suslow and W. Schweigkofler (NORS-DUC) for providing samples; M. Forrest (TwistDx Inc.) for advice in developing the nested and sequencing techniques using RPA; and P. Tooley (United States Department of Agriculture-Agricultural Research Service) and G. Bilodeau (Canadian Food Inspection Agency) for critical reading of the manuscript and for helpful discussions. Mention of trade names or commercial products in this article is solely for the purpose of providing specific information and does not imply recommendation or endorsement by the United States Department of Agriculture.

\section{LITERATURE CITED}

1. Anonymous. Phytophthora PathoScreen Kit: Alkaline Phosphatase Label, Catalog Number PSA 92600. Agdia Inc., Elkhart, IN.

2. Avila, F. J., Schoedel, B., Abad, Z. G., Coffey, M. D., and Blomquist, C. 2010. ELISA and ImmunoStrip for detection of Phytophthora ramorum, P. kernoviae, and other Phytophthora species. Pages 378 in: Proc. Sudden Oak Death Fourth Sci. Symp. Gen. Tech. Rep. PSW-GTR-229. U. S. Dep. Agric. For. Serv. Pac. Southwest Res. Stn. Albany, CA.

3. Barber, P., Paap, T., Burgess, T., Dunstan, W., and Hardy, G. S. J. 2013. A diverse range of Phytophthora species are associated with dying urban trees. Urban For. Urban Green. 12:569-575.

4. Bilodeau, G., Pelletier, G., Pelletier, F., Hamelin, R. C., and Lévesque, C. A. 2009. Multiplex real-time polymerase chain reaction (PCR) for detection of Phytophthora ramorum, the causal agent of sudden oak death. Can. J. Plant Pathol. 31:195-210.

5. Bilodeau, G. J., Coffey, M. D., Blomquist, C., and Martin, F. 2014. Development of a multiplex assay for genus and species specific detection 
of Phytophthora based on differences in mitochondrial gene order. Phytopathol. 104: 733-748.

6. Bilodeau, G. J., Lévesque, C., De Cock, A., Duchaine, C., Brière, S., Uribe, P., Martin, F., and Hamelin, R. 2007. Molecular detection of Phytophthora ramorum by real-time polymerase chain reaction using TaqMan, SYBR Green, and molecular beacons. Phytopathology 97:632642 .

7. Blair, J. E., Coffey, M. D., Park, S. Y., Geiser, D. M., and Kang, S. C. 2008. A multi-locus phylogeny for Phytophthora utilizing markers derived from complete genome sequences. Fungal Genet. Biol. 45:266277.

8. Brasier, C. M., Beales, P. A., Kirk, S. A., Denman, S., and Rose, J. 2005. Phytophthora kernoviae sp. nov., an invasive pathogen causing bleeding stem lesions on forest trees and foliar necrosis of ornamentals in the UK. Mycol. Res. 109:853-859.

9. Chen, Q., Li, B., Liu, P., Lan, C., Zhan, Z., and Weng, Q. 2013. Development and evaluation of specific PCR and LAMP assays for the rapid detection of Phytophthora melonis. Eur. J. Plant Pathol. 137:597-607.

10. Chomczynski, P., and Rymaszewski, M. 2006. Alkaline polyethylene glycol-based method for direct PCR from bacteria, eukaryotic tissue samples, and whole blood. Biotechniques 40:454.

11. Craw, P., and Balachandran, W. 2012. Isothermal nucleic acid amplification technologies for point-of-care diagnostics: A critical review. Lab on a Chip 12:2469-2486.

12. Dai, T. T., Lu, C. C., Lu, J., Dong, S., Ye, W., Wang, Y., and Zheng, X. 2012. Development of a loop-mediated isothermal amplification assay for detection of Phytophthora sojae. FEMS Microbiol. Lett. 334:27-34.

13. Drenth, A., Wagels, G., Smith, B., Sendall, B., O’Dwyer, C., Irvine, G., and Irwin, J. 2006. Development of a DNA-based method for detection and identification of Phytophthora species. Australas. Plant Pathol. 35:147-159.

14. Erwin, D. C., and Ribeiro, O. K. 1996. Phytophthora Diseases Worldwide. American Phytopathological Society, St. Paul, MN.

15. Garbelotto, M., Rizzo, D., Hayden, K., Meija-Chang, M., Davidson, J. M., and Tjosvold, S. A. 2002. Phytophthora ramorum and sudden oak death in California: III. Preliminary studies on pathogen genetics. Pages 765-774 in: U. S. Dep. Agric. For. Ser. Gen. Tech. PSW-GTR-184, 5th Symp. Calif. Oak Woodlands. R. Sandiford, and D. McCreary, eds.

16. Hüberli, D., Hardy, G. S. J., White, D., Williams, N., and Burgess, T. 2013. Fishing for Phytophthora from Western Australia's waterways: A distribution and diversity survey. Australas. Plant Pathol. 42:251-260.

17. Hussain, S., Lees, A., Duncan, J., and Cooke, D. 2005. Development of a species-specific and sensitive detection assay for Phytophthora infestans and its application for monitoring of inoculum in tubers and soil. Plant Pathol. 54:373-382.

18. Jeffers, S. N., and Martin, S. B. 1986. Comparison of two media selective for Phytophthora and Pythium species. Plant Dis. 70:1038-1043.

19. Jung, T., and Burgess, T. I. 2009. Re-evaluation of Phytophthora citricola isolates from multiple woody hosts in Europe and North America reveals a new species, Phytophthora plurivora sp. nov. Persoonia 22:95-110.

20. Jung, T., Stukely, M., Hardy, G., White, D., Paap, T., Dunstan, W., and Burgess, T. 2011. Multiple new Phytophthora species from ITS Clade 6 associated with natural ecosystems in Australia: Evolutionary and ecological implications. Persoonia: Mol. Phylogenet. Evol. Fungi 26:13-39.
21. Kox, L. F. F., van Brouwershaven, I. R., van de Vossenberg, B. T. L. H. van den Beld, H. E., Bonants, P. J. M., and de Gruyter, J. 2007. Diagnostic values and utility of immunological, morphological, and molecular methods for in planta detection of Phytophthora ramorum. Phytopathology 97:1119-1129.

22. MacDonald, J., Stites, J., and Kabashima, J. 1990. Comparison of serological and culture plate methods for detecting species of Phytophthora, Pythium, and Rhizoctonia in ornamental plants. Plant Dis. 74:655-659.

23. Martin, F. N., Abad, Z.G., Balci, Y., and Ivors, K. 2012. Identification and detection of Phytophthora: Reviewing our progress, identifying our needs. Plant Dis. 96:1080-1103.

24. Martin, F. N., Blair, J. E., and Coffey, M. D. 2014. A combined mitochondrial and nuclear multilocus phylogeny of the genus Phytophthora. Fungal Genet. Biol. 66:19-32.

25. Martin, F. N., Tooley, P. W., and Blomquist, C. 2004. Molecular detection of Phytophthora ramorum, the causal agent of sudden oak death in California, and two additional species commonly recovered from diseased plant material. Phytopathology 94:621-631.

26. Nagel, J. H., Gryzenhout, M., Slippers, B., Wingfield, M. J., Hardy, G. E. S. J., Stukely, M. J., and Burgess, T. I. 2013. Characterization of Phytophthora hybrids from ITS clade 6 associated with riparian ecosystems in South Africa and Australia. Fungal Biol. 117:329-347.

27. Piepenburg, O. 2013. TwistAmp DNA Amplification Kits-Combined Instruction Manual. Twistdx Ltd., Cambridge, UK.

28. Schena, L., Duncan, J., and Cooke, D. 2008. Development and application of a PCR-based 'molecular tool box' for the identification of Phytophthora species damaging forests and natural ecosystems. Plant Pathol. 57:64-75.

29. Schena, L., Hughes, K. J. D., and Cooke, D. E. L. 2006. Detection and quantification of Phytophthora ramorum, $P$. kernoviae, $P$. citricola and $P$. quercina in symptomatic leaves by multiplex real-time PCR. Mol. Plant Pathol. 7:365-379.

30. Tomlinson, J., Dickinson, M., and Boonham, N. 2010. Rapid detection of Phytophthora ramorum and $P$. kernoviae by two-minute DNA extraction followed by isothermal amplification and amplicon detection by generic lateral flow device. Phytopathology 100:143-149.

31. Tooley, P. W., Martin, F. N., Carras, M. M., and Frederick, R. D. 2006 Real-time fluorescent polymerase chain reaction detection of Phytophthora ramorum and Phytophthora pseudosyringae using mitochondrial gene regions. Phytopathology 96:336-345.

32. USDA-APHIS. 2004. Sudden oak death: Phytophthora ramorum. In: Pest Detection and Management Programs. L. Levy, and V. Mavrodieva, eds. USDA Animal Plant Health Inspection Service.

33. Vincent, M., Xu, Y., and Kong, H. 2004. Helicase-dependent isothermal DNA amplification. EMBO Rep. 5:795-800.

34. Winton, L., and Hansen, E. 2001. Molecular diagnosis of Phytophthora lateralis in trees, water, and foliage baits using multiplex polymerase chain reaction. For. Pathol. 31:275-283.

35. Zhang, X., Zhang, H., Pu, J., Qi, Y., Yu, Q., Xie, Y., and Peng, J. 2013. Development of a real-time fluorescence loop-mediated isothermal amplification assay for rapid and quantitative detection of Fusarium oxysporum f. sp. cubense tropical race 4 in soil. PLoS One 8:e82841. 